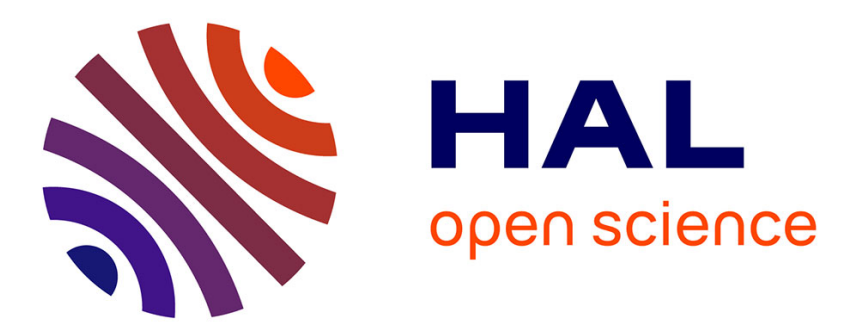

\title{
New constraints on the chemical composition and outgassing of $67 \mathrm{P} /$ Churyumov-Gerasimenko
}

\author{
C. Herny, O. Mousis, R. Marschall, N. Thomas, M. Rubin, O. \\ Pinzón-Rodríguez, I.P. P Wright
}

\section{- To cite this version:}

C. Herny, O. Mousis, R. Marschall, N. Thomas, M. Rubin, et al.. New constraints on the chemical composition and outgassing of 67P/Churyumov-Gerasimenko. Planetary and Space Science, 2021, 200, pp.105194. 10.1016/j.pss.2021.105194 . insu-03319265

\section{HAL Id: insu-03319265 \\ https://hal-insu.archives-ouvertes.fr/insu-03319265}

Submitted on 12 Aug 2021

HAL is a multi-disciplinary open access archive for the deposit and dissemination of scientific research documents, whether they are published or not. The documents may come from teaching and research institutions in France or abroad, or from public or private research centers.
L'archive ouverte pluridisciplinaire $\mathbf{H A L}$, est destinée au dépôt et à la diffusion de documents scientifiques de niveau recherche, publiés ou non, émanant des établissements d'enseignement et de recherche français ou étrangers, des laboratoires publics ou privés. 


\section{Journal Pre-proof}

New constraints on the chemical composition and outgassing of 67P/ChuryumovGerasimenko

C. Herny, O. Mousis, R. Marschall, N. Thomas, M. Rubin, O. Pinzón-Rodríguez, I.P. Wright

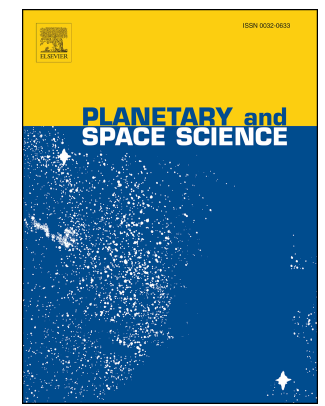

PII:

S0032-0633(21)00033-7

DOI: https://doi.org/10.1016/j.pss.2021.105194

Reference: PSS 105194

To appear in: Planetary and Space Science

Received Date: 24 April 2020

Revised Date: 25 January 2021

Accepted Date: 25 February 2021

Please cite this article as: Herny, C., Mousis, O., Marschall, R., Thomas, N., Rubin, M., PinzónRodríguez, O., Wright, I.P., New constraints on the chemical composition and outgassing of 67P/ Churyumov-Gerasimenko, Planetary and Space Science, https://doi.org/10.1016/j.pss.2021.105194.

This is a PDF file of an article that has undergone enhancements after acceptance, such as the addition of a cover page and metadata, and formatting for readability, but it is not yet the definitive version of record. This version will undergo additional copyediting, typesetting and review before it is published in its final form, but we are providing this version to give early visibility of the article. Please note that, during the production process, errors may be discovered which could affect the content, and all legal disclaimers that apply to the journal pertain.

(C) 2021 Published by Elsevier Ltd. 
Clémence Herny: Conceptualization, Software, Validation, Formal analysis, Writing Original Draft, Visualization. Olivier Mousis: Conceptualization, Supervision, Resources, Writing - Review \& Editing. Raphael Marschall: Conceptualization, Resources, Writing Review \& Editing. Nicolas Thomas: Conceptualization, Resources, Supervision, Writing Review \& Editing. Martin Rubin: Resources, Writing - Review \& Editing. Olga PinzónRodríguez: Writing - Review \& Editing. Ian P. Wright: Writing - Review \& Editing. 
${ }^{a}$ Physikalisches Institut, Universität Bern, Sidlerstrasse 5, 3012 Bern, Switzerland

${ }^{\mathrm{b}}$ Aix Marseille Université, CNRS, LAM (Laboratoire d'Astrophysique de Marseille) UMR 7326, F-

${ }^{\mathrm{c}}$ Southwest Research Institute, 1050 Walnut St., Boulder, CO 80302, USA

d Open University, School of Physical Sciences, Walton Hall, Milton Keynes MK7 6AA, Bucks, England

* Corresponding author: clemence.herny@space.unibe.ch

Abstract

Strong heterogeneities in the composition of the volatile species have been detected in the coma of comet 67P/Churyumov-Gerasimenko (67P/C-G) by the ROSINA instrument onboard the ESA's Rosetta spacecraft. However, it is not clear if these heterogeneities are indicative of heterogeneities in the near-surface nucleus composition or if the coma composition is mainly insolation-driven. In order to clarify the link between the composition of the nucleus and the composition of the coma we have performed numerical simulations and compare our results with measurements acquired by ROSINA/DFMS for three major volatile species namely, $\mathrm{H}_{2} \mathrm{O}, \mathrm{CO}_{2}$, and CO. We use a previously published thermo-physical numerical model designed to study cometary nucleus evolution, including volatile outgassing and internal stratigraphy, as the comet orbits the Sun. The model follows schemes used for much of the past three decades to model cometary outgassing. Our results match well the experimental volatiles density measurements of ROSINA/DFMS for most of the Rosetta mission. They suggest that the outgassing pattern is mainly insolation-driven and the variations are caused by the tilt of rotation axis and eccentricity of the nucleus. The nucleus shows to 
$1^{\text {st }}$ order a homogeneous composition and therefore we can provide constraints on the bulk volatiles composition of 67P/C-G nucleus which is dominated by $\mathrm{H}_{2} \mathrm{O}(91.4 \% \pm 4.5 \%)$, then $\mathrm{CO}_{2}(6.7 \% \pm$ $3.5 \%)$ and $\mathrm{CO}$ in small amount $(1.9 \% \pm 1.2 \%)$. However, in details, a dichotomy in composition between the northern and southern hemispheres of the comet is revealed. $\mathrm{A} \mathrm{CO} / \mathrm{CO}_{2}$ bulk composition ratio of about $0.6 \pm 0.1$ is required to reproduce the measurements from the northern hemisphere and about $0.2 \pm 0.1$ for the southern hemisphere. To match the data, the thermal properties of the nucleus surface must be modified by adding a thin desiccated dust mantle $(\sim 5 \mathrm{~mm})$ for northern latitudes while this appears not to be necessary for southern latitudes. This may be related to the observed dichotomy in putative airfall deposits. We suspect that, because of thermal inertia, seasonally non-illuminated areas continue to outgas and influence the ROSINA measurements. This effect cannot be reproduced with the model. Therefore during some periods of the mission, the fits are not ideal. Finally, the outgassing of the different ices leads to a layered internal structure defined by the sublimation front of each ice and formation of harder layers close to the surface due to sublimation/condensation processes. However, the thermo-physical model overestimates the absolute volatiles production (mainly in the southern hemisphere) leading to an overestimation of the erosion rates. Further investigations will be performed to improve the thermo-physical model and the sensitivity analysis.

Keywords: comet 67P/Churyumov-Gerasimenko; comet composition and internal structure; volatiles outgassing; thermal modelling of cometary nucleus; ROSINA/DFMS data

\section{Introduction}

Comets are thought to have retained a pristine internal structure since the formation of the Solar System. Therefore studying their composition and internal structure may provide constraints on conditions present in the protoplanetary disk. But determining their composition and internal structure is challenging because, following the problems with the Philae lander (Boehnhardt et al. 2017), our main sources of information were acquired remotely. We can get an idea of the species present in cometary nuclei by analysing the gas emitted from the surface into the coma. Although instruments 
detect heterogeneity in the abundances of species in the coma of different comets (Krankowsky et al. 1986, Feaga et al., 2007, A'Hearn et al., 2011, Hässig et al., 2015, Hoang et al., 2017, 2019), it is not clear that this indicates compositional heterogeneity of the nucleus itself (Hässig et al., 2015, Fink et al., 2016). The ROSINA/DFMS mass spectrometer (Balsiger et al., 2007) on board the European Space Agency's Rosetta spacecraft has measured the density of various species at the location of the spacecraft inside the coma of comet 67P/Churyumov-Gerasimenko (hereafter 67P/C-G). Results display strong variations of the relative abundances of major volatiles in the coma (Hässig et al., 2015). Several studies proposed that the complex shape of the nucleus and the large tilt of the rotation axis of 67P/C-G of $52^{\circ}$ (Sierks et al., 2015, Brugger et al. 2016) would imply large daily and seasonal effects driving the species outgassing (De Sanctis et al., 2010, Fougere et al., 2016, Fink et al., 2016, Fulle et al., 2016b) while others suggest that the diversity of surface morphologies of 67P/C-G results from non-uniform sub-surface composition (Vincent et al., 2015; Mousis et al., 2015, Keller et al., 2017). While previous studies of comets from fly-bys and ground-based observations have been thorough, even the detailed observations of $67 \mathrm{P} / \mathrm{C}-\mathrm{G}$ by the Rosetta spacecraft have failed to provide a clear answer to the question of whether comets are predominantly homogeneous in composition or not (Hässig et al., 2015).

The present study attempts to address this complicated issue by comparing the volatiles density measurements provided by the ROSINA/DFMS instrument with a thermo-physical numerical model based on the work of Marboeuf et al., $(2008,2012)$ designed to follow the evolution of a nucleus as it outgasses. Previous studies have provided estimates of the bulk composition of 67P/C-G using indirect methods (Rubin et al., 2019, Combi et al., 2020, Läuter et al., 2019, Bockelée-Morvan et al., 2016, Biver et al., 2019). With this direct approach, we can combine, for the first time, both the influence of the chemical composition and the physical properties of the nucleus to understand the complex relation between the outgassing nucleus and its resulting coma.

In the following section, we shall discuss the dataset to be modelled, the model itself and the applied boundary conditions. In Section 3, we shall present detailed comparisons of the model results with the data. In Section 4 we present insight on surface evolution and internal structure. Sections 5 and 6 provide the usual discussion and conclusions. 
2. Data and method

87

a. Mass spectrometry measurements

The ROSINA (Rosetta Orbiter Spectrometer for Ion and Neutral Analysis) experiment (Balsiger et al., 2007) comprises three complementary instruments dedicated to monitor the composition, gas speed, and temperature of the neutral gas coma. Among this suite of instruments, we used the data acquired by the DFMS (Double Focusing Mass Spectrometer) which is a high resolution mass spectrometer. It acquired a mass spectrum during $~ 50 \mathrm{~min}$ from mass/charge $13-100 \mathrm{u} / \mathrm{e}$ in steps of $1 \mathrm{u} / \mathrm{e}$ providing the relative bulk composition (relative abundance) of the coma at the time of the measurement at the location of Rosetta. Using the pressure sensor COPS (COmetary Pressure Sensor) then allows obtaining absolute densities of the different species (Gasc et al. 2017, Rubin et al. 2019). The orbiting spacecraft explored different sub-spacecraft latitudes and longitudes of the comet throughout the measurement periods (Section 2.d, Fig. 4), however, it must be pointed out that gas may originate from any location within the field of view of ROSINA.
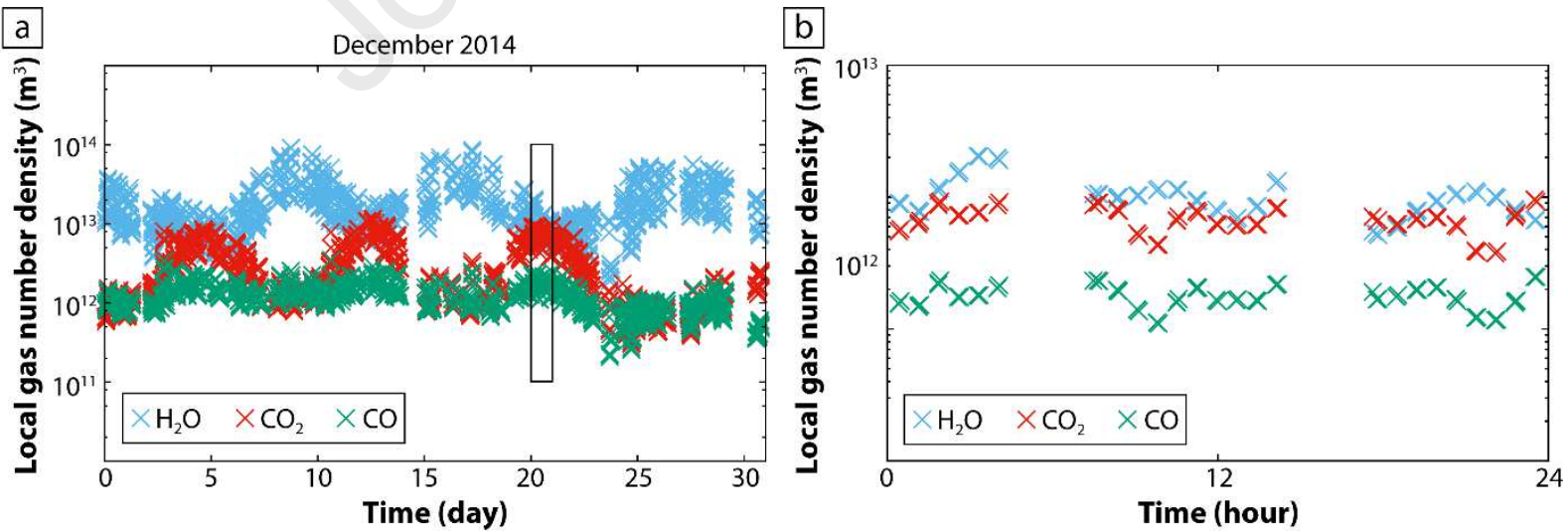

Fig. 1: (a) Local gas number density evolution of $\mathrm{H}_{2} \mathrm{O}$ (blue crosses), $\mathrm{CO}_{2}$ (red crosses), and $\mathrm{CO}$ (green crosses) measured by ROSINA on board Rosetta for the period of December 2014. (b) Detail from $20^{\text {th }}$ December highlighted by the black box in (a). 
(Fig. 1) (Le Roy et al., 2015; Hässig et al., 2015). Temporal and spatial variabilities of the coma composition have been detected (Hässig et al., 2015). It appears that sometimes the production of $\mathrm{CO}_{2}$ and $\mathrm{CO}$ exceeds that of $\mathrm{H}_{2} \mathrm{O}$ and that $\mathrm{CO}_{2}$ and $\mathrm{CO}$ vary with respect to $\mathrm{H}_{2} \mathrm{O}$ (Fig. 1, before equinox, Fougere et al., 2016). Errors in the ROSINA number density are dependent upon the combination of the two instruments COPS and DFMS. The error in the absolute density provided by COPS is $<15 \%$ (Kramer et al. 2017) and the error in the relative abundances provided by DFMS is $<30 \%$ (Rubin et al. 2019; Läuter et al. 2020).

b. The comet nucleus numerical model

The production rates of species coming out from the nucleus have been investigated via a numerical model. The model is based upon work carried out by Klinger in the 1990s (e.g. Klinger et al., 1996, Klinger, 1999) but the specific implementation is that of Marboeuf et al., (2008, 2012, 2014). We note that several other models of the evolution of cometary nuclei have been published and used in the past. A summary of many of these can be found in Huebner (2002).

The model was designed to compute the thermal and chemical evolution of the (sub)-surface of a single point at a given cometary latitude, $\lambda$, of the nucleus along the comet's orbit around the Sun (Fig. 2). The nucleus is considered to be a porous sphere made of a mixture of ices and dust grains defined in specified proportions. At the beginning of the simulation, ices and dust grains are homogeneously mixed in the porous matrix, up to the nucleus surface. The cometary grains are defined as spherical and compact refractory dust grains encased by volatile ices (Marboeuf et al., 2012). This assumption is consistent with one of the theory proposed to explain the aggregation of material in protoplanetary disks and comets (Greenberg et al., 1998, Huebner et al., 2006, Schoonenberg and Ormel, 2017, Mousis et al., 2018). The nucleus has an initially defined radius, R, and rotation period, T, around its rotation axis, $\Omega$. The model computes, amongst other quantities, the heat conduction and evolution at different depths, the sublimation/condensation of volatiles within the nucleus, the gas diffusion through a porous medium and the sublimation front of different ices along 
the comet's orbit around the Sun. The model can also take into account the presence of a dust mantle at the surface.

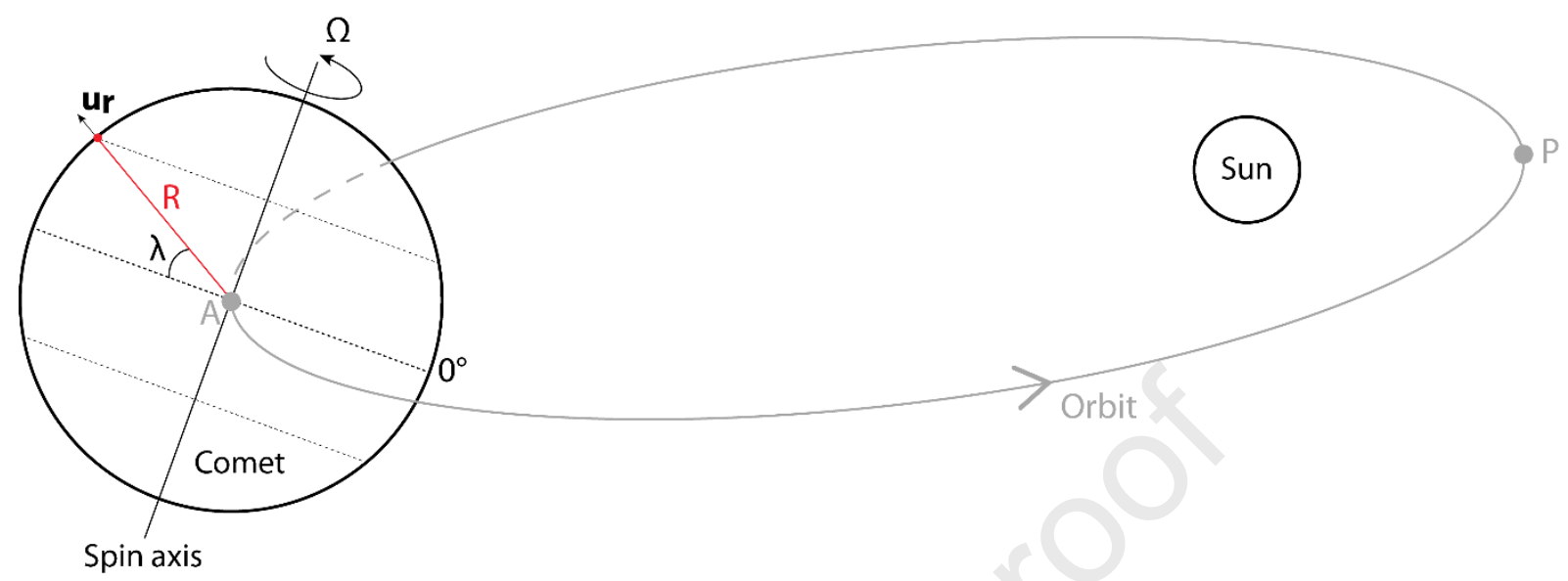

Fig. 2: Principle of the numerical model. The comet is considered to be a spherical object with radius,

R. Outputs of the model are computed in $1 \mathrm{D}$ along the $u_{r}$ vector for a given latitude $\lambda$ while the comet is rotating around its spin axis $\Omega$ and on its orbit around the Sun. The two points, A and P, correspond to the aphelion and perihelion positions respectively.

The model solves the linked equations for conservation of energy and mass, described in detail in Marboeuf et al. (2012). They are solved by the finite volume method, in spherical coordinates and in one dimension, along the radial vector $\mathrm{u}_{\mathrm{r}}$ (Fig. 2). Lateral processes are neglected. The gas diffuses through the pores by a flow mechanism defined by the Knudsen number. Even if the comet is far from a sphere (Preusker et al., 2015; Jorda el al., 2016), the spherical approximation is suitable to study a single point that is not subject to shadowing by other surface facets. We note that areas on the surface of 67P/C-G's nucleus experience significant shadowing affecting the energy input and therefore the outgassing (Keller et al. 2015b). However, we aim to focus on the chemical composition and not bring additional complexity to the already sophisticated thermo-physical model with a 3D complex shape and illumination that will increase the computational times beyond what we can reasonably be achieved. A 3D model taking into account of the physical and chemical aspects of the presented 1D numerical model (Marboeuf et al. 2012, 2014) has not been developed so far. We can say, however, that this simplification leads to an overestimation of the outgassing, a point that will be addressed in 
157

158

159

160

161

162

163

164

165

166

167

168

169

170

171

172

173

174

175

176

177

178

179

180

181

182

183

184

section 2.d. The numerical domain takes into account the whole comet radius with the nucleus centre placed at $\mathrm{z}=0$ and surface at $\mathrm{z}=\mathrm{R}$. The surface temperature is computed with an energy balance equation and the centre temperature is set as a Neumann condition. The model uses a spatial discretization in a grid in which equations are computed for every numerical layer. The discretization comprises (1) a fixed number of layers with a minimum thickness, placed just below the surface to ensure good spatial resolution as most of the driving processes occur close to the surface (solar heating, sublimation of volatiles, evolution of the radius, dust mantle) because of the low thermal conductivity (Section 2.c) and then (2) an exponential increase of the layer thickness, for a given number of layers, from the sub-surface to the centre of the nucleus. The number of layers, and therefore their thicknesses, evolve as the sublimation/condensation of ices occurs. In effect, the code is solving Stefan's problem. The temporal discretization follows the corrector-predictor scheme developed by Espinasse et al. (1991) with the complementary use of an implicit scheme and a semiimplicit scheme avoiding instabilities and improving accuracy. Numerical tests have shown that results from the model have a high degree of confidence because the error in the mass conservation does not exceed $0.1 \%$ for the global error and $1 \%$ for the local error at a given time, $\mathrm{t}$ (Marboeuf, 2008).

c. Input parameters

Characteristic properties of $67 \mathrm{P} / \mathrm{C}-\mathrm{G}$ are used as inputs to the model and are presented in Table 1. The comet has an orbital period of 6.44 years with an aphelion at $5.68 \mathrm{AU}$ and perihelion at 1.24 AU. The last perihelion occurred on 13 August 2015 (1.24 AU), the $1^{\text {st }}$ equinox on 11 May 2015 $(1.67 \mathrm{AU})$ and the $2^{\text {nd }}$ equinox on 20 March 2016 (2.62 AU). At the time of the rendezvous of the Rosetta spacecraft with 67P/C-G, the period of rotation of the comet was about $12.40 \mathrm{~h}$ (Mottola et al., 2014). We acknowledge that the observed spin-up of the nucleus (Keller et al. 2015a, Accomazzo et al. 2017) could not be implemented in the model at this stage. The orientation of the spin axis with respect to the orbit is defined by (1) the obliquity $\Omega$, which is about $52.25^{\circ}$ (Jorda et al., 2016) and (2) the argument of the subsolar meridian at perihelion set at $-110.50^{\circ}$ (Brugger et al., 2016). 

protoplanetary disk during comet formation (Yamamoto, 1985) and temperature derived from ortho-

187 para ratio of water vapour in comets (Mumma et al. 1987)) and the radius of the comet is initially set to $2 \mathrm{~km}$. This evolves as the comet approaches the Sun. The nucleus has a porosity of $\sim 75 \%$ (Kofman et al., 2015, Pätzold et al., 2016; Taylor et al., 2017) with an averaged pore radius assumed to be of $10^{-4} \mathrm{~m}$ (Huebner, 2006). The dust-to-ice mass ratio (D/I), is uncertain (Choukroun et al., 2020), but we choose a value of 4 (Rotundi et al., 2015) and photometric measurements revealed that the comet has a low albedo of about 0.05 (Feaga et al., 2015, Ciarniello, et al. 2015, Fornasier et al., 2016). The dust properties were set for a silicate composition (Ellsworth and Schubert, 1983 and Krause et al., 2011). The solid dust density is set to $2600 \mathrm{~kg} \mathrm{~m}^{-3}$ (Pätzold et al. 2016, Herique et al. 2016, Fulle et al. 2017, Pätzold et al. 2019). The dust grain radius has been chosen to vary from $10^{-6}$ to $10^{-2} \mathrm{~m}$ following a power law size distribution with exponent -3.5 (e.g. Huebner et al., 2006, e.g. Marboeuf et al., 2012). These values are in agreement with results and uncertainties obtained during the Rosetta mission (Fulle et al. 2016a, Langevin et al. 2016, Merouane et al. 2017, Choukroun et al. 2020, Marschall et al. 2020a) and imply a limited amount of particles greater than $1 \mathrm{~cm}$ (Marschall et al. 2020a). However, a single power law may not fit properly the data over the whole dust size range and it should be noticed that while large particles are not abundant, they might represent most of the dust mass (Fulle et al. 2016). For the given parameters the bulk density of the nucleus computed with the numerical model ranged between 475 and $510 \mathrm{~kg} \mathrm{~m}^{-3}$, according to volatile content, which is close to the pre-perihelion bulk density evaluated to $537.8 \pm 0.6 \mathrm{~kg} \mathrm{~m}^{-3}$ (Pätzold et al., 2019). Similarly, the thermal inertia evolved between 60 and $90 \mathrm{~J} \mathrm{~K}^{-1} \mathrm{~m}^{-2} \mathrm{~s}^{-1 / 2}$ which is in the range of the estimated thermal inertia from 10 to $150 \mathrm{~J} \mathrm{~K}^{-1} \mathrm{~m}^{-2} \mathrm{~s}^{-1 / 2}$ (Groussin et al., 2019). Due to the low thermal inertia, the thermal conductivity of the nucleus layers is computed with the Hertz factor formula. The choice of thermodynamic properties and laws for ices are extensively detailed in Marboeuf et al., (2012). The model is also able to handle the different ice phases and transitions (crystalline, amorphous and clathrates). Some studies proposed the presence of different ice phases in the nucleus (Mousis et al., 2015), however, for simplicity, we only consider crystalline ices in this study. 
thickness of $1 \mathrm{~mm}$ (without dust mantle) or $5 \mathrm{~mm}$ (with dust mantle) immediately below the surface.

These thicknesses are comparable to or thicker than the dust grains considered in our size distribution but do not properly represent the potential case in which most of the dust is contained in large particles. The thicknesses of the layers increase exponentially to the nucleus centre. The simulations were performed over several orbits with a variable time step depending on the heliocentric distance varying between $15 \mathrm{~s}$ to $7.5 \mathrm{~min}$. All the presented results have converged both with time step and space step. For all the simulations the initial parameters presented in Table 1 were kept constant.

\begin{tabular}{|c|c|c|}
\hline Parameter & Value & Reference \\
\hline Semi-major axis (AU) & 3.46 & Maquet (2015) \\
\hline Eccentricity & 0.64 & Maquet (2015) \\
\hline Orbital period (yr) & 6.44 & Maquet (2015) \\
\hline Aphelion position (AU) & 5.68 & \\
\hline Aphelion date & 21 May 2012 & \\
\hline $1^{\text {st }}$ Equinox position (AU) & 1.67 & \\
\hline $\mathbf{1}^{\text {st }}$ Equinox date & 11 May 2015 & \\
\hline Perihelion position (AU) & 1.24 & \\
\hline Perihelion date & 13 August 2015 & \\
\hline $2^{\text {nd }}$ Equinox position (AU) & 2.62 & \\
\hline $2^{\text {nd }}$ Equinox date & 20 March 2016 & \\
\hline Rotation period (hr) & 12.4043 & Mottola et al. (2014) \\
\hline Obliquity (deg) & 52.25 & Sierk et al. (2015), Brugger et al. (2016) \\
\hline Argument of subsolar meridian at perihelion (deg) & -110.50 & Brugger et al. (2016) \\
\hline Comet radius $(\mathbf{k m})$ & 2.00 & \\
\hline Initial porosity & $75 \%$ & Taylor et al. (2017) \\
\hline Pore radius $(\mathbf{m})$ & $10^{-4}$ & Huebner et al. (2006) \\
\hline Dust to ice mass ratio & 4.00 & Rotundi et al. (2015) \\
\hline Bolometric albedo & 0.05 & Taylor et al. (2017) \\
\hline Emissivity & 0.95 & Spohn et al. (2015) \\
\hline Initial temperature $(\mathbf{K})$ & 30 & \\
\hline Dust density $\left(\mathrm{kg} \mathrm{m}^{-3}\right)$ & 2600 & Pätzold et al. $(2016,2019)$ \\
\hline Heat capacity of dust $\left(\mathrm{J} \mathrm{kg}^{-1} \mathrm{~K}^{-1}\right)$ & 770 & Prialnik et al. (2004) \\
\hline Dust thermal conductivity (W $\mathbf{m}^{-1} \mathbf{K}^{-1}$ ) & 4.00 & Ellsworth and Schubert (1983) \\
\hline Range size of dust grains (m) & $10^{-6}$ to $10^{-2}$ & Marboeuf et al. (2014) \\
\hline
\end{tabular}

Table 1: Modelling parameters for the nucleus 67P/C-G. 

input parameters. These were treated as free parameters in order to observe their influence on the outgassing pattern and to fit the observations.

The thermo-physical model and input parameters provide the evolution of the absolute production rate of volatiles at the surface of the spherical comet (Fig. 3). Outgassing rates obtained at different latitudes (Section 2.e, Fig. 5) have also been integrated separately over the northern hemisphere and over the southern hemisphere for one comet orbit. The results are scaled with a free parameter referred to as the Effective Active Fraction (EAF) translating the fact that the surface of the comet is not fully active. An EAF of $20 \%$ is applied to our volatiles outgassing to match the observed total volatiles loss and maximum production peak (Marschall et al., 2017, 2020a, Läuter et al., 2019, 2020, Combi et al., 2020). This value is higher than the typical evaluated value of about $1 \%$ used by other groups (Gulkis et al., 2015, Marschall, et al., 2020b), which is a consequence of the subsurface

\section{Normalized orbital phase}

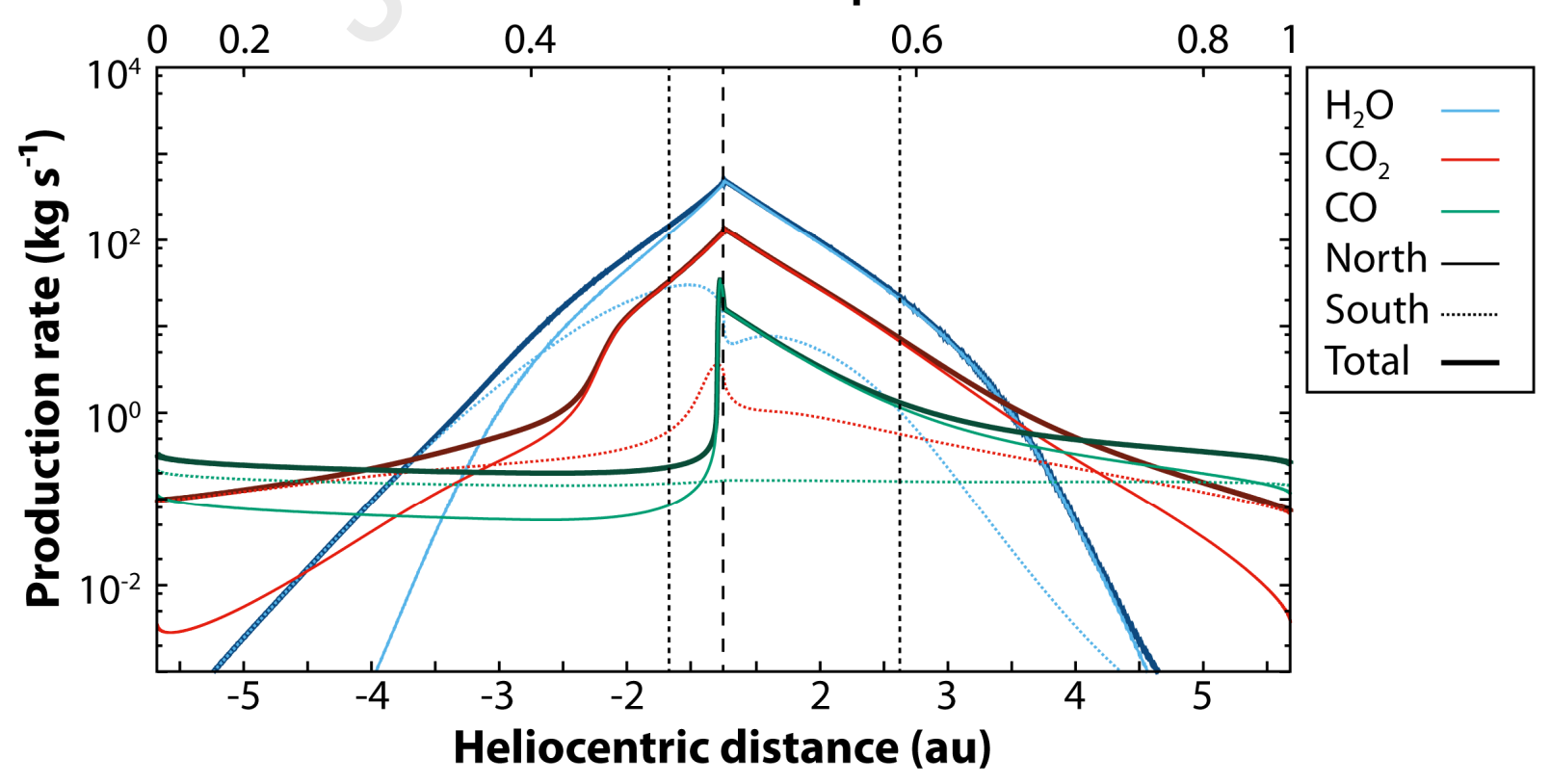


241 Fig. 3: Production rate $\left(\mathrm{kg} \mathrm{s}^{-1}\right)$ of $\mathrm{H}_{2} \mathrm{O}, \mathrm{CO}_{2}$ and $\mathrm{CO}$ as function of the heliocentric distance $\mathrm{r}_{\mathrm{h}}(\mathrm{au})$ and normalized orbital phase. The production rates have been integrated over the spherical surface for latitudes of the northern hemisphere (December 2014 bulk composition, Table 2) and of the southern hemisphere (November 2015 bulk composition, Table 2), corresponding to solid and dotted lines, respectively. The EAF is $20 \%$. The sum of the two hemispheres corresponds to the bold lines. The perihelion is highlighted by vertical black dashed line and equinoxes by vertical pointed black lines.

With an EAF of $20 \%$, we obtained a total $\mathrm{H}_{2} \mathrm{O}$ loss over the entire orbit of $7.3 \times 10^{9} \mathrm{~kg}$ which is the same order of magnitude as previous estimates from measurements $\left(6.4 \times 10^{9} \mathrm{~kg}\right.$ Hansen et al. (2016), $4.9 \times 10^{9} \mathrm{~kg}$, Combi et al. (2020), $6.1 \times 10^{9}$ Marshall et al. (2020a), $4.0 \times 10^{9} \mathrm{~kg}$, Läuter et al. (2020)). The peak of $\mathrm{H}_{2} \mathrm{O}$ production occurs about 6 days after perihelion with a production rate of about $4.9 \times 10^{2} \mathrm{~kg} \mathrm{~s}^{-1}\left(\sim 1.6 \times 10^{28}\right.$ molecules $\left.\mathrm{s}^{-1}\right)$ for the southern hemisphere and about 60 days before perihelion with a production rate of about $\left.3.0 \times 10^{1} \mathrm{~kg} \mathrm{~s}^{-1}\left(\sim 1.0 \times 10^{27} \text { molecules s}\right)^{-1}\right)$ for the northern hemisphere. The production rate obtained for the southern hemisphere (and the global production) is consistent with previously estimated $\mathrm{H}_{2} \mathrm{O}$ peak production based on measurements analysis with values on the order of $5.0 \times 10^{2} \mathrm{~kg} \mathrm{~s}^{-1}\left(3.5 \pm 0.5 \times 10^{28}\right.$ molecules s${ }^{-1}$, Hansen et al., 2016 (total $\mathrm{H}_{2} \mathrm{O}$ production), $1.4 \pm 0.5 \times 10^{28}$ molecules s ${ }^{-1}$, Marshall et al., 2017 (total production), $2.0 \pm 0.1 \times 10^{28}$ molecules s${ }^{-1}$, Läuter et al., 2019 (total production and southern hemisphere production), $2.8 \times 10^{28}$ molecules s ${ }^{-1}$, Combi et al. 2020 (total production), $2.7 \times 10^{28}$ molecules s ${ }^{-1}$, Marschall et al. 2020a, 1.8 x $10^{28}$ molecules $\mathrm{s}^{-1}$, Läuter et al., 2020 (total production)). However, the value obtained for the northern hemisphere appears to be underestimated (by a factor of about 5) by the thermo-physical model compared to DFMS/COPS measurements analyse $\left(\mathrm{H}_{2} \mathrm{O}\right.$ peak of production rate for northern hemisphere is about $1.8 \times 10^{2} \mathrm{~kg} \mathrm{~s}^{-1}$, Läuter et al. (2019)). In addition, our thermo-physical model does not reproduce well the time shift of peak production that is observed to be about 20 days after perihelion (Hansen et al. 2016).

With an EAF of $20 \%$, we obtained over the entire orbit a total $\mathrm{CO}_{2} \operatorname{loss}$ of $2.0 \times 10^{9} \mathrm{~kg}$ and a total CO loss of $2.5 \times 10^{8} \mathrm{~kg}$ which is on the same order of magnitude as previous estimates $\left(8.8 \times 10^{8}\right.$ $\mathrm{kg}$ and $2.1 \times 10^{8} \mathrm{~kg}$ respectively, Combi et al. (2020) and $7.2 \times 10^{8} \mathrm{~kg}$ and $1.9 \times 10^{8} \mathrm{~kg}$ respectively, 
Läuter et al. (2020)). The peak of $\mathrm{CO}_{2}$ production occurs about 6 days after perihelion and gives a production rate of about $1.3 \times 10^{2} \mathrm{~kg} \mathrm{~s}^{-1}\left(\sim 1.8 \times 10^{27}\right.$ molecules $\left.\mathrm{s}^{-1}\right)$ for the southern hemisphere and

271

272

273 about 27 days before perihelion and gives a production rate of about $3.6 \mathrm{~kg} \mathrm{~s}^{-1}\left(\sim 5.0 \times 10^{25}\right.$ molecules s ${ }^{1}$ ) for the northern hemisphere. Finally, the peak of $\mathrm{CO}$ production occurs at perihelion and gives a production rate of about $3.4 \times 10^{1} \mathrm{~kg} \mathrm{~s}^{-1}\left(\sim 7.4 \times 10^{26}\right.$ molecules $\left.\mathrm{s}^{-1}\right)$ for the southern hemisphere and about 3 days before perihelion and gives production rate of about $1.7 \times 10^{-1} \mathrm{~kg} \mathrm{~s}^{-1}\left(\sim 3.6 \times 10^{24}\right.$ molecules $\mathrm{s}^{-1}$ ) for the northern hemisphere. Note the difference in the time at which the maxima are reached here when compared to $\mathrm{H}_{2} \mathrm{O}$. As for $\mathrm{H}_{2} \mathrm{O}$ production rates, the results obtained for the southern hemisphere match the observation for an EAF of $20 \%\left(1.6 \times 10^{27}\right.$ molecules s ${ }^{-1}$ and $5.9 \times 10^{26}$ molecules s ${ }^{-1}$ for the maximum production of $\mathrm{CO}_{2}$ and $\mathrm{CO}$ respectively, Läuter et al., 2020) while for the northern hemisphere the value are underestimated by a factor of about 5 relative to other calculations.

The total production rates are dominated by the southern hemisphere contribution within about $3.5 \mathrm{au}$ in our results (Fig. 3). The slopes of the integrated volatiles production as function of the heliocentric distance $\left(\mathrm{r}_{\mathrm{h}}\right)$ have been calculated with a power law $\left(\sim \mathrm{r}_{\mathrm{h}}{ }^{\alpha}\right)$ for a chosen range between 3.5 to 3.5 au corresponding to the Rosetta mission range. For $\mathrm{H}_{2} \mathrm{O}$, we obtained a steeper slope before perihelion than after with $\alpha$ values of -4.2 and -3.6 respectively. The value before perihelion is consistent with previous studies based on measurements analyses (values between -3.8 to -7.0) while our results after perihelion is lower (values between -4.3 to -7.1) (Hansen et al., 2016, Marshall et al., 2017, 2020a, Shinnaka et al., 2017, Läuter et al., 2019). Our slopes match the observations better than the significantly lower slope (about -2.8 for the model A) provided by the thermal model of Keller et al. (2015b). For $\mathrm{CO}_{2}$, we obtained $\alpha$ value of -3.5 after perihelion, and for $\mathrm{CO}$, we obtained $\alpha$ values of -3.3 after perihelion (the slope values before perihelion are not satisfactory (asymptotic standard error $>5 \%$ ) fit with the power law), corresponding to slightly lower slopes obtained for the $\mathrm{H}_{2} \mathrm{O}$ production rate after perihelion. Slopes obtained for $\mathrm{CO}_{2}$ and $\mathrm{CO}$, respectively, are lower than the slopes obtained by Läuter et al. (2019) (-4.5 and -6 for $\mathrm{CO}_{2}$ and $\mathrm{CO}$ respectively). 
rates but clearly the existing model does not produce a perfect fit. For example, the different EAF require to fit the production rates in the northern and southern hemisphere are likely caused by the presence of a desiccated dust mantle at the surface of the nucleus for the northern plains inhibiting the outgassing while ices are present up to the nucleus surface in the southern hemisphere (Section 2.e and Table 2). But there are perhaps alternative structural models that could be defined that would provide better fits. Nonetheless, it is encouraging that the model essentially derived from first principles can approach observed values.

e. Strategy of data comparison

ROSINA collected data at different latitudes and distances from the nucleus following the spacecraft orbit (Fig. 4). However, the exact location in the coma is not implemented in the numerical model. Therefore we choose to study the dimensionless volatiles density ratios measured in the coma by ROSINA/DFMS $\left(\mathrm{CO} / \mathrm{CO}_{2}, \mathrm{CO}_{2} / \mathrm{H}_{2} \mathrm{O}\right.$ and $\left.\mathrm{CO} / \mathrm{H}_{2} \mathrm{O}\right)$ to avoid gas density extrapolation corrections caused by the spacecraft-comet distance. We also assume that the three species have the same equal acceleration profiles and so the measurement of the ratios at a distance from the surface would be unchanged from the surface. In addition, we ran numerical simulations for different sub-spacecraft latitudes explored by Rosetta. The sub-spacecraft latitude corresponds to the angle between the spacecraft projection at the nucleus surface and the equator. It is independent of the nucleus shape. We consider that the projected latitude of the spacecraft on the nucleus corresponds to the latitude of gas release. This approach does not capture any lateral flow that might occur as a result of the gas flow dynamics (e.g. Kitamura, 1985). It should be noted that this effect can strongly influence the gas densities close to the terminator and might influence ratios of species because of the different molecular masses and initial velocities. 

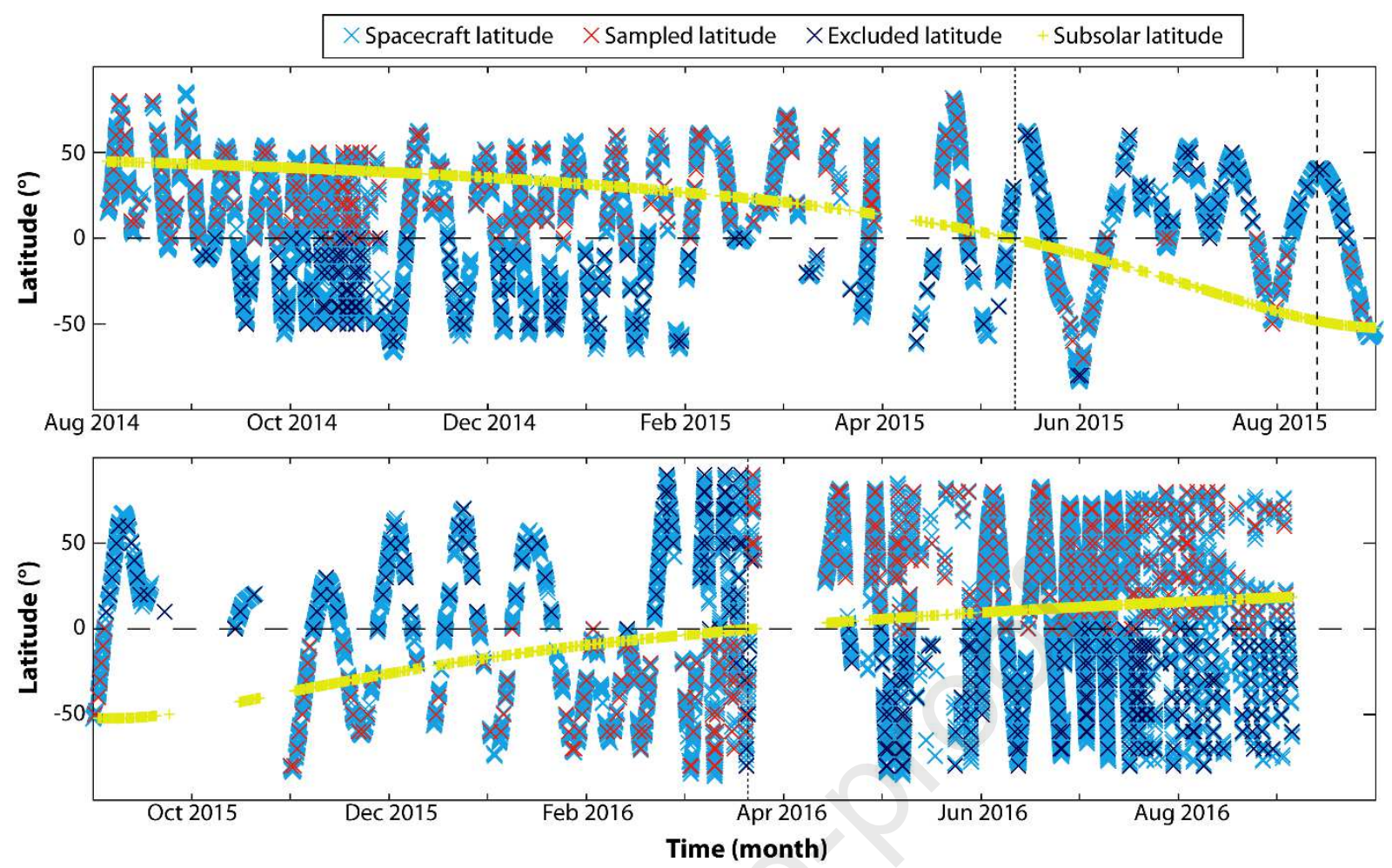

Fig. 4: Latitudes sampled by the numerical model (red crosses) compared to the Rosetta subspacecraft latitudes projection onto the surface (blue crosses) of the comet. Some sampled values were excluded (dark blue crosses) as numerical results are obtained for incidence angles above $90^{\circ}$. The subsolar latitude (yellow crosses) of the comet $67 \mathrm{P} / \mathrm{C}-\mathrm{G}$ is also indicated. The northern hemisphere is illuminated before the $1^{\text {st }}$ equinox and after the $2^{\text {nd }}$ equinox. Between the equinoxes and trough perihelion passage, the southern hemisphere is illuminated. The perihelion is highlighted by the vertical black dashed line and equinoxes by vertical pointed black lines.

We performed numerical simulations for latitudes between $90^{\circ} \mathrm{S}$ to $90^{\circ} \mathrm{N}$ with a $10^{\circ}$ increment. If a ROSINA measurement was available for the given latitude (within bounds of $\pm 2^{\circ}$ ), we extracted the numerical result at the corresponding time (Fig. 4). Numerical results obtained for an incidence angle above $90^{\circ}$ are excluded (Fig. 5 a and b). The calculated gas density drops drastically on the night side (Fig. 6), especially for $\mathrm{H}_{2} \mathrm{O}$, which might not be the case in reality because of lateral gas flow and/or non-insolation driven emission and hence comparisons at incidence angles greater than $90^{\circ}$ are likely to be misleading. This selection excluded mostly southern latitudes results for 
periods before and after the $1^{\text {st }}$ and $2^{\text {nd }}$ equinox, respectively, and mostly northern latitudes for period in-between the equinoxes (Fig. $5 \mathrm{c}$ and d).

a

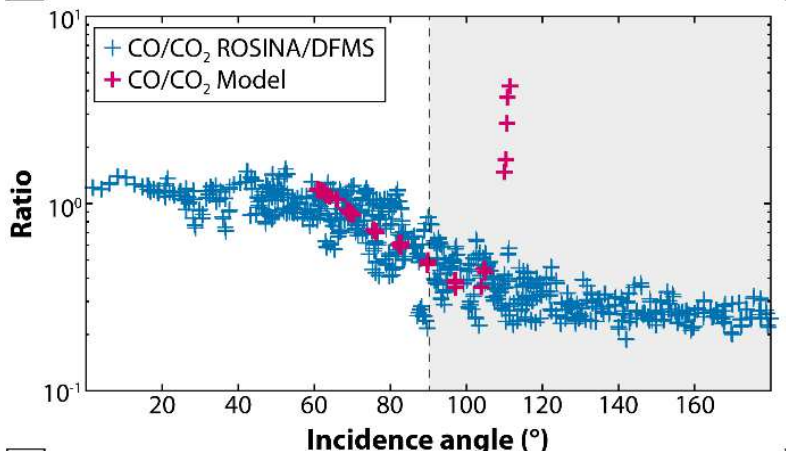

b

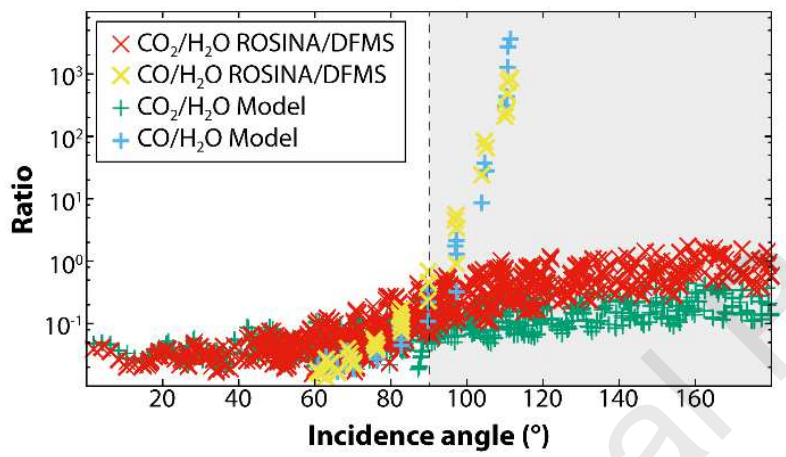

C

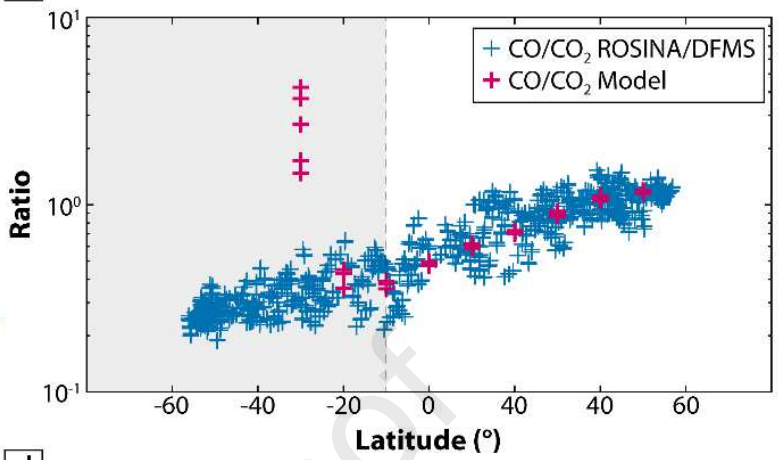

d

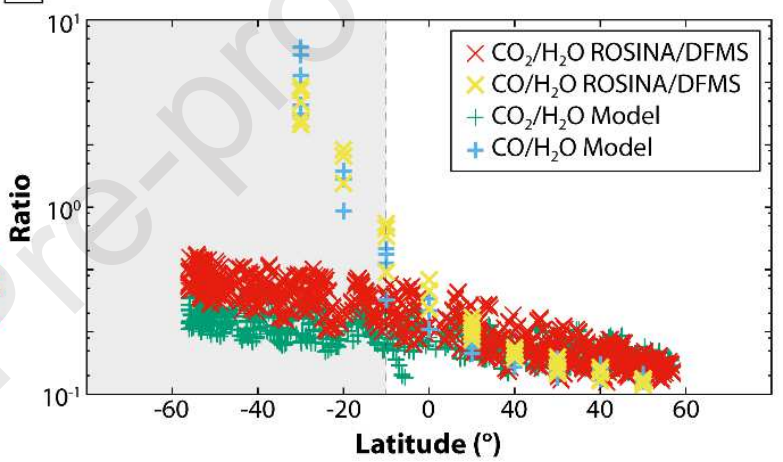

Fig. 5: Evolution of the $\mathrm{CO} / \mathrm{CO}_{2}$ (a) and $\mathrm{CO}_{2} / \mathrm{H}_{2} \mathrm{O}$ and $\mathrm{CO} / \mathrm{H}_{2} \mathrm{O}$ (b) density ratios with incidence angle of ROSINA and results from numerical modelling. Evolution of the $\mathrm{CO} / \mathrm{CO}_{2}$ (c), $\mathrm{CO}_{2} / \mathrm{H}_{2} \mathrm{O}$ and $\mathrm{CO} / \mathrm{H}_{2} \mathrm{O}$ (d) density ratios with latitude of ROSINA and results from numerical modelling. The grey areas highlight, respectively, the incidence angles (right areas on panels a and b) and latitudes (left areas on panels $\mathrm{c}$ and d) for which computed values diverge and are excluded for the study. Model results above $90^{\circ}$ incidence angle (a and b left) and below latitude $-50^{\circ}$ ( $\mathrm{c}$ and $\mathrm{d}$ right), respectively, are out of scale. The results are presented for December 2014.

To compare our results efficiently with the measurements we averaged the computed results of density ratios. As mentioned above, $\mathrm{H}_{2} \mathrm{O}$ exhibits large outgassing variation over many orders of magnitude (Fig. 6) induced by its presence at or close to the surface (Section 4) and consequently is highly sensitive to illumination variations. Therefore, differences with respect to the time of the sampled data with the instrument lead to large errors in the production rate of $\mathrm{H}_{2} \mathrm{O}$ compared to 
experimental measurements. In addition, the outgassing of $\mathrm{H}_{2} \mathrm{O}$ is highly dependent on the complex

shape of the comet and it has been shown that some areas are more active than others (Marschall et al., 2017). Finally, the instrument receives contributions from adjacent latitudes/longitudes resulting from the gas expansion process. This tends to smooth the signal recorded. By averaging the modelling data over one comet rotation (12h40) we significantly improved the coherence of our results for the comparison with ROSINA measurements (Fig. 7a). The averaging of the $\mathrm{CO} / \mathrm{CO}_{2}$ density ratio is less affected because these species are mostly located below the surface (Section 4, Fig. 13) and are therefore less sensitive to the day-night cycle. The production rate of $\mathrm{CO}_{2}$ varies by less than 3 orders of magnitude in the southern hemisphere in-between equinoxes, while it is almost constant in the northern hemisphere before the $1^{\text {st }}$ equinox (Fig. 6). CO outgassing is almost constant in both periods.

a

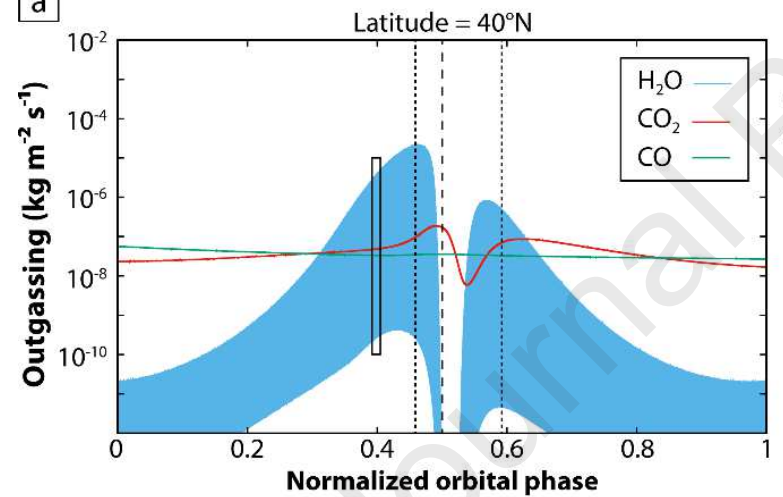

b

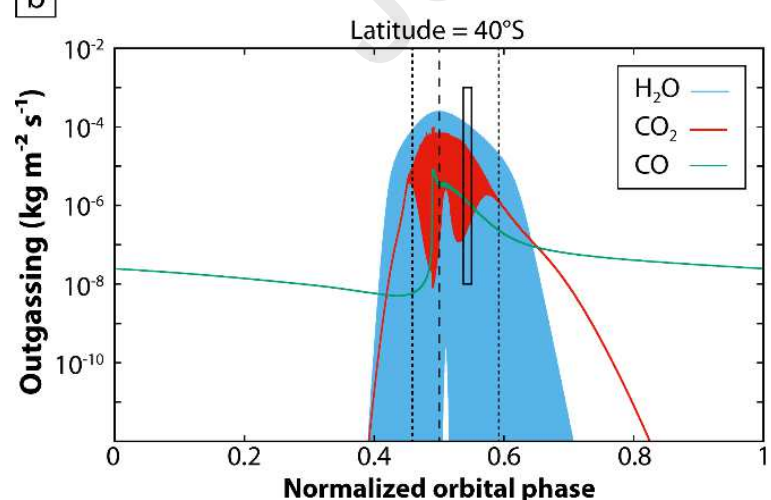

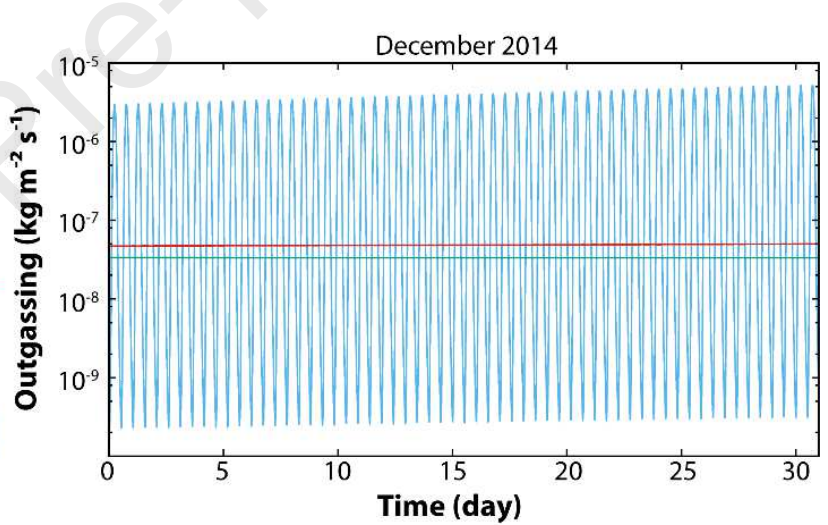

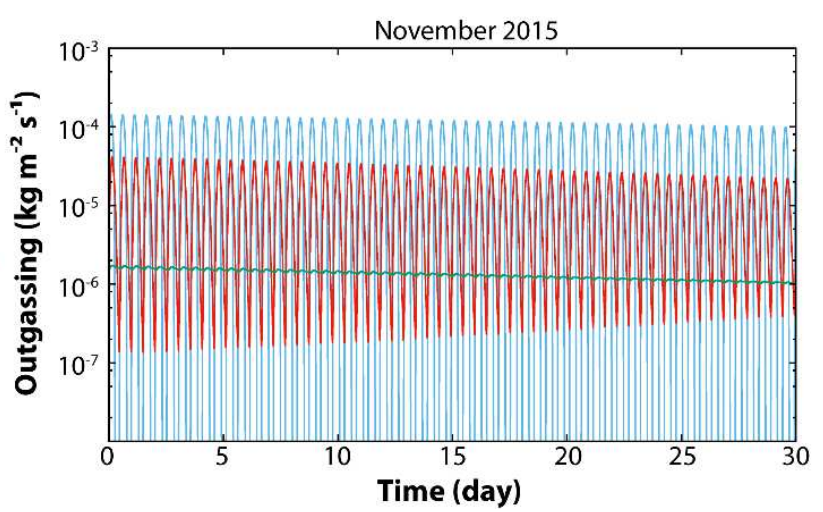

Fig. 6: Evolution of the outgassing rates $\left(\mathrm{kg} \mathrm{m}^{-2} \mathrm{~s}^{-1}\right)$ of $\mathrm{H}_{2} \mathrm{O}$ (blue), $\mathrm{CO}_{2}$ (red) and $\mathrm{CO}$ (green) computed at (a) latitudes $40^{\circ} \mathrm{N}$ (December 2014 bulk composition) and (b) $40^{\circ} \mathrm{S}$ (November 2015 bulk composition) over one orbital period ( 6.44 yrs). The right panels are zooms (highlighted in the left 
panel by a black box) over one month. The perihelion is highlighted by vertical black dashed line and equinoxes by vertical pointed black lines on the left panels.

To reproduce the volatiles density measured in the coma by ROSINA/DFMS, the initial bulk composition of the three studied species in the nucleus were modified until we found the best combination to fit the volatiles density ratios measurements in the coma with the given fixed parameters (Table 1). Following, we refer to the volatiles abundance ratio, in the coma as the volatiles density ratios and, in the nucleus as the volatiles bulk composition ratios. For simplicity, we split the timeline according to month and found the best fit composition for each month by calculating correlation criteria which are (1) the calculated density ratio over the measured density ratio averaged over the given month and (2) iterating to minimize the Root Mean Square Error (RMSE, Table 2). Simulation for which the calculated density ratio is different by more than $50 \%$ of the measured density ratio and/or with a RMSE above 1 are considered unreliable and excluded from averaging calculations. The results presented here are for different epochs but we will now focus on the results for December 2014. At this time, the spacecraft was close to the nucleus (Fougere et al., 2016) and far from the Sun and hence the effects of collisions in the flow and reaction chemistry in the coma were at a low level. The presence of a dust mantle at the surface has also been treated as a free parameter. This choice has been motivated by the fact that the presence (or not) of a substantial dust mantle at the surface of 67P/C-G is a direct observation from the OSIRIS camera (Thomas et al., 2015a and 2015b) and it is known that the dust mantle has an effect on the outgassing (Huebner et al., 2006, Marboeuf et al., 2014). Therefore, if the addition of a dust mantle improves the fit (i.e. the calculated density ratio over the measured ratio values are getting closer to 1 and/or RMSE is reduced) of the calculated density ratios $\mathrm{CO} / \mathrm{CO}_{2}, \mathrm{CO}_{2} / \mathrm{H}_{2} \mathrm{O}$ and $\mathrm{CO} / \mathrm{H}_{2} \mathrm{O}$ with ROSINA/DFMS measurements, then we select the results obtained with the dust mantle. Following testing, its thickness is kept constant at $5 \mathrm{~mm}$, corresponding to the best fit obtained for December 2014, and the dust grains freed from the nucleus by sublimation, are assumed to escape.

All simulations were run first without dust mantle at the surface for several orbits until the modelled nucleus reached a steady-state. In our case, this was reached after a few orbits and we choose 
to present data obtained during the $5^{\text {th }}$ orbit. After this time, the results do not evolve (Fig. 7a). This

400

401

402

403

404

405

406

407

a
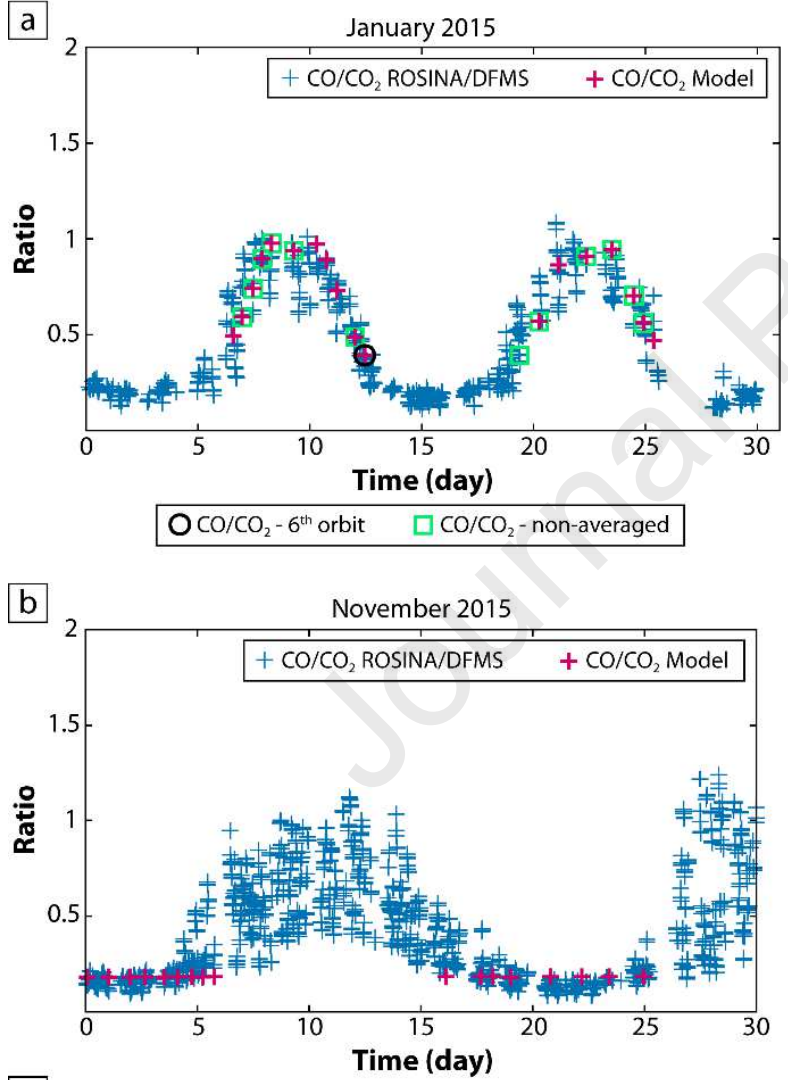

C

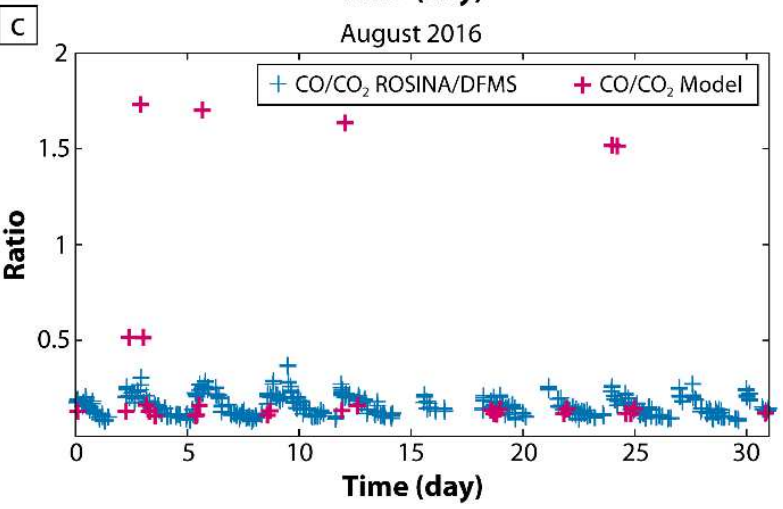

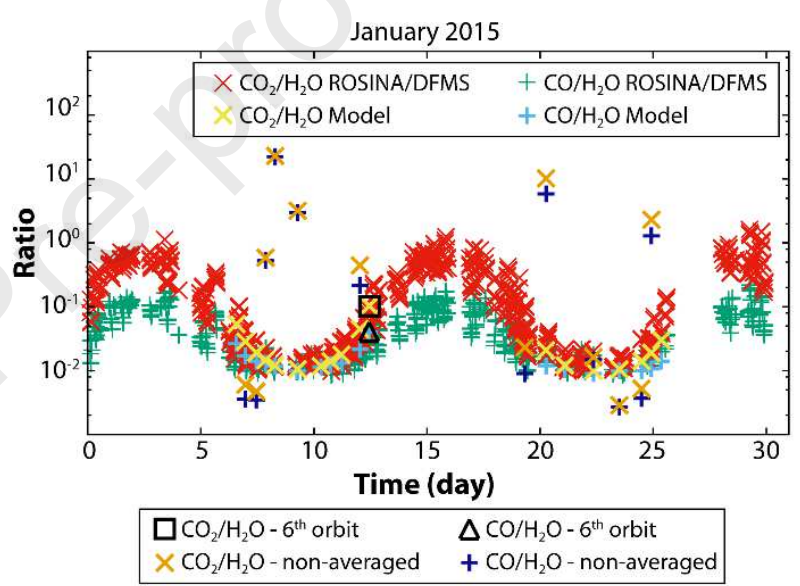
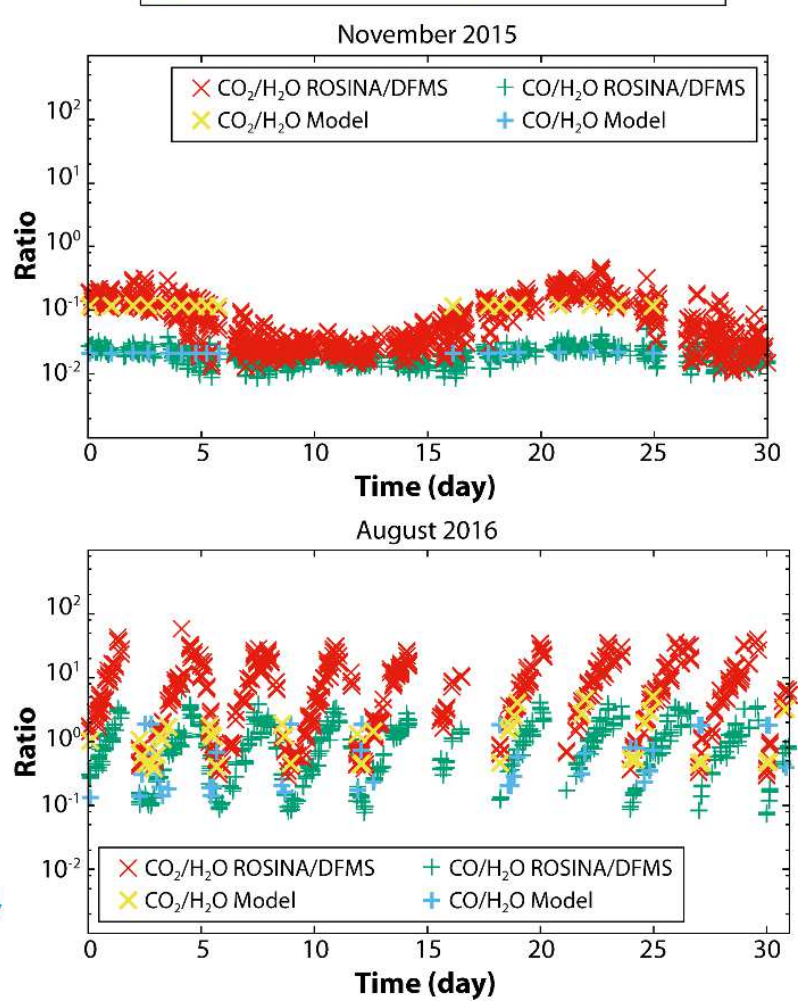
corresponds to a total of time of 32.2 years which is consistent with the last major change in the orbit of 67P/C-G (Maquet et al., 2015). The initiation of the dust mantle deposition at the surface of 67P/C$\mathrm{G}$ is unknown. It is likely that before the recent change of orbit (Maquet et al., 2015), bringing the comet close to the Sun, there was no dust mantle at the surface of 67P/C-G. In addition, the dust mantle experiences erosion and restoration phases (Groussin et al., 2015, Fornasier et al., 2016, Hu et al., 2017). Then, in case the presence of a dust mantle is required, it has been added at the beginning of the $5^{\text {th }}$ orbit, disturbing the steady-state of the nucleus beyond the end of the $5^{\text {th }}$ orbit. 
Fig. 7: Comparison of density ratios $\mathrm{CO} / \mathrm{CO}_{2}$ (left, pink crosses) and $\mathrm{CO}_{2} / \mathrm{H}_{2} \mathrm{O}$ and $\mathrm{CO} / \mathrm{H}_{2} \mathrm{O}$ (right, blue crosses and yellow crosses, respectively) computed by the numerical model with the data measured by ROSINA/DFMS (blue crosses, green crosses and red crosses, respectively) for (a) January 2015, (b) November 2015 and (c) August 2016. The numerical results have been averaged over one comet spin period. The bulk composition and dust mantle thickness set for each month are presented in Section 3.d (Table 2 and Fig. 12). (a) In the January 2015 plots, black circles, squares and triangles correspond respectively to $\mathrm{CO} / \mathrm{CO}_{2}, \mathrm{CO}_{2} / \mathrm{H}_{2} \mathrm{O}$ and $\mathrm{CO} / \mathrm{H}_{2} \mathrm{O}$ density ratios obtained at the equator and for the $6^{\text {th }}$ orbit (while results in pink are obtained at the $5^{\text {th }}$ orbit) and show that the model has converged. The light green, orange and dark blue crosses correspond to the non-averaged results of the numerical model. It does not affect the value of $\mathrm{CO} / \mathrm{CO}_{2}$ but might exclude some points as the incidence angle is averaged as well.

Finally, the bulk compositions of the different volatiles do not vary, at the scale of the nucleus, through the five comet orbits. Therefore the composition at the sampling time corresponds to the initial bulk composition set for each month.

\section{Nucleus outgassing pattern}

\section{a. Comparison of evolution of $\mathrm{CO} / \mathrm{CO}_{2}$ density ratios}

Our simulation results match the $\mathrm{CO} / \mathrm{CO}_{2}$ density ratios measured by ROSINA/DFMS satisfactory for most epochs (Figs. 7 and 8 and Table 2), especially with regards to the absolute error values of the ROSINA measured gas ratios (Section 2.a) and uncertainties in the fixed parameters (Table 1). Indeed, for the 15 months (of a total of 26) fulfilling the correlation criteria (calculated density ratio over measured density ratio is no different by more than $50 \%$ of the measured ratio and with a RMSE below 1), the average calculated density ratio over measured density ratio is 1.01 and the average RMSE is 0.23 . We have established with the thermo-physical model both, (1) the correct range of magnitude of $\mathrm{CO} / \mathrm{CO}_{2}$ density ratios, between $1.0 \times 10^{-2}$ and 3 , and (2) fit the evolutionary 
437 trend of $\mathrm{CO} / \mathrm{CO}_{2}$ density ratios, observed by ROSINA/DFMS for most parts. The $\mathrm{CO} / \mathrm{CO}_{2}$ density 438 ratio oscillates around 1 showing that, depending upon the time and insolation, CO outgassing can 439 surpass $\mathrm{CO}_{2}$ and vice versa in both measurements and model. The $\mathrm{CO} / \mathrm{CO}_{2}$ density ratios reach values 440 of up to 3 before perihelion and below 1 for most of the post perihelion period.

441 

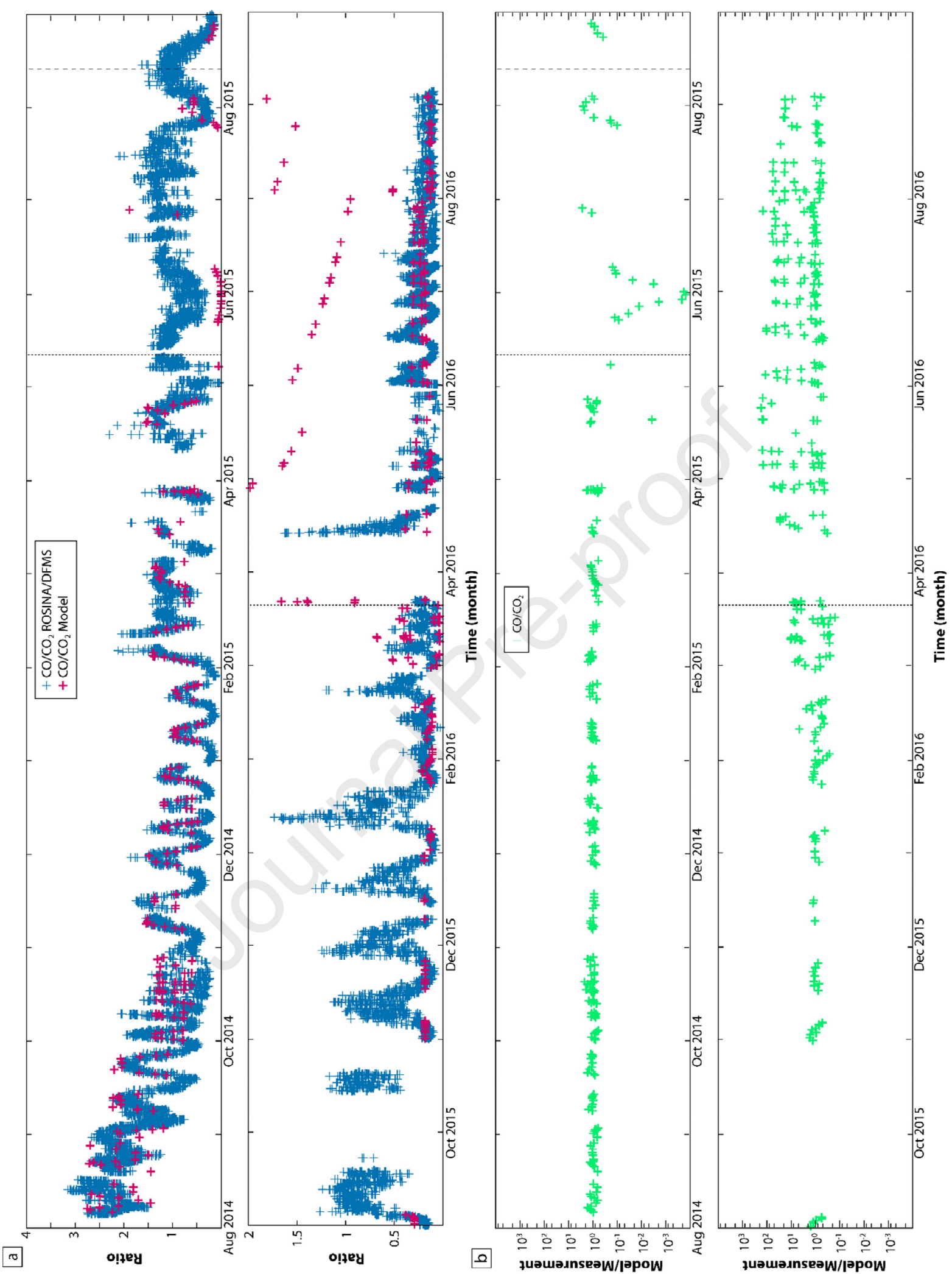

Fig. 8: (a) Comparison of the $\mathrm{CO} / \mathrm{CO}_{2}$ density ratio computed by the numerical model (pink crosses) with the data measured by ROSINA/DFMS (blue crosses) during the Rosetta mission. The bulk composition and dust mantle thickness set for each month are presented in Section 3.d (Table 2). (b)

446 Ratio of the calculated to the measured $\mathrm{CO} / \mathrm{CO}_{2}$ density ratio (green crosses). The $1^{\text {st }}$ and $2^{\text {nd }}$ 
equinoxes are highlighted by vertical black dotted lines and perihelion by the vertical black dashed line.

For some months the correlation is not satisfying. This is particularly true around the equinoxes (April, May and June 2015 and March, April and May 2016) with an average calculated density ratio over measured density ratio of 11.3 and an average RMSE of 25.5. For these periods, we have difficulty reproducing both the magnitude and the trend (Fig. 8). Despite the trend is mostly reproduced for several months after the $2^{\text {nd }}$ equinox (June to September 2016, although some data points are out of magnitude, Fig. 7), the correlation criteria do not match with an average calculated density ratio over measured density ratio of 10.53 and the average RMSE of 5.18.

\section{b. Comparison of evolution of $\mathrm{CO}_{2} / \mathrm{H}_{2} \mathrm{O}$ and $\mathrm{CO} / \mathrm{H}_{2} \mathrm{O}$ density ratios}

\section{ROSINA/DFMS are also satisfactory (Figs. 7 and 9 and Table 2). Indeed, for the 15 months (over 26)} fulfilling the correlation criteria, the average calculated density ratio over measured density ratio is 1.07 for $\mathrm{CO}_{2} / \mathrm{H}_{2} \mathrm{O}$ and 0.97 for $\mathrm{CO} / \mathrm{H}_{2} \mathrm{O}$ and the average RMSE is 0.16 for $\mathrm{CO}_{2} / \mathrm{H}_{2} \mathrm{O}$ and 0.15 for $\mathrm{CO} / \mathrm{H}_{2} \mathrm{O}$. We have reproduced both the magnitude and the trend for several epochs, especially between November 2014 and April 2015 and between August 2015 and February 2016. Times when $\mathrm{CO}_{2} / \mathrm{H}_{2} \mathrm{O}$ exceeded $\mathrm{CO} / \mathrm{H}_{2} \mathrm{O}$ were correctly reproduced. However, similar to the $\mathrm{CO} / \mathrm{CO}_{2}$ density ratio, for some months the agreement between measurements and results is inferior. At the beginning of the mission (August to October 2014) the trends are reproduced but not the magnitude of the ratios. As with the $\mathrm{CO} / \mathrm{CO}_{2}$ density ratios, the fits are not satisfying for the months around the equinoxes (April, May and June 2015 and March, April and May 2016), especially for $\mathrm{CO} / \mathrm{H}_{2} \mathrm{O}$. The average calculated density ratio over measured density ratio is 39.71 for $\mathrm{CO}_{2} / \mathrm{H}_{2} \mathrm{O}$ and $>1000$ for $\mathrm{CO} / \mathrm{H}_{2} \mathrm{O}$ and the average RMSE is 42.0 for $\mathrm{CO}_{2} / \mathrm{H}_{2} \mathrm{O}$ and $>100$ for $\mathrm{CO} / \mathrm{H}_{2} \mathrm{O}$. Finally, after the $2^{\text {nd }}$ equinox (June to September 2016), the numerical results match poorly the ROSINA measurements (Figs. 7c and 8) for the $\mathrm{CO} / \mathrm{H}_{2} \mathrm{O}$ density ratios. The average calculated ratio over measured ratio is 21.04 and the average 
475 RMSE is 6.23 for $\mathrm{CO} / \mathrm{H}_{2} \mathrm{O}$. However, we notice an improvement of the fit for $\mathrm{CO}_{2} / \mathrm{H}_{2} \mathrm{O}$ density ratios 476 toward the end of the mission with an average calculated density ratio over measured density ratio of 4771.23 and an average RMSE of 0.98 . For this ratio, the trend and magnitude of the values are mostly 478 reproduced (Fig. 7c and 9 and Table 2). Because of weak reliability of the computations performed for 479 after the $2^{\text {nd }}$ equinox, we have focused our efforts on reducing the RMSE and matching the measured 480 value of $\mathrm{CO}_{2} / \mathrm{H}_{2} \mathrm{O}$.

481 


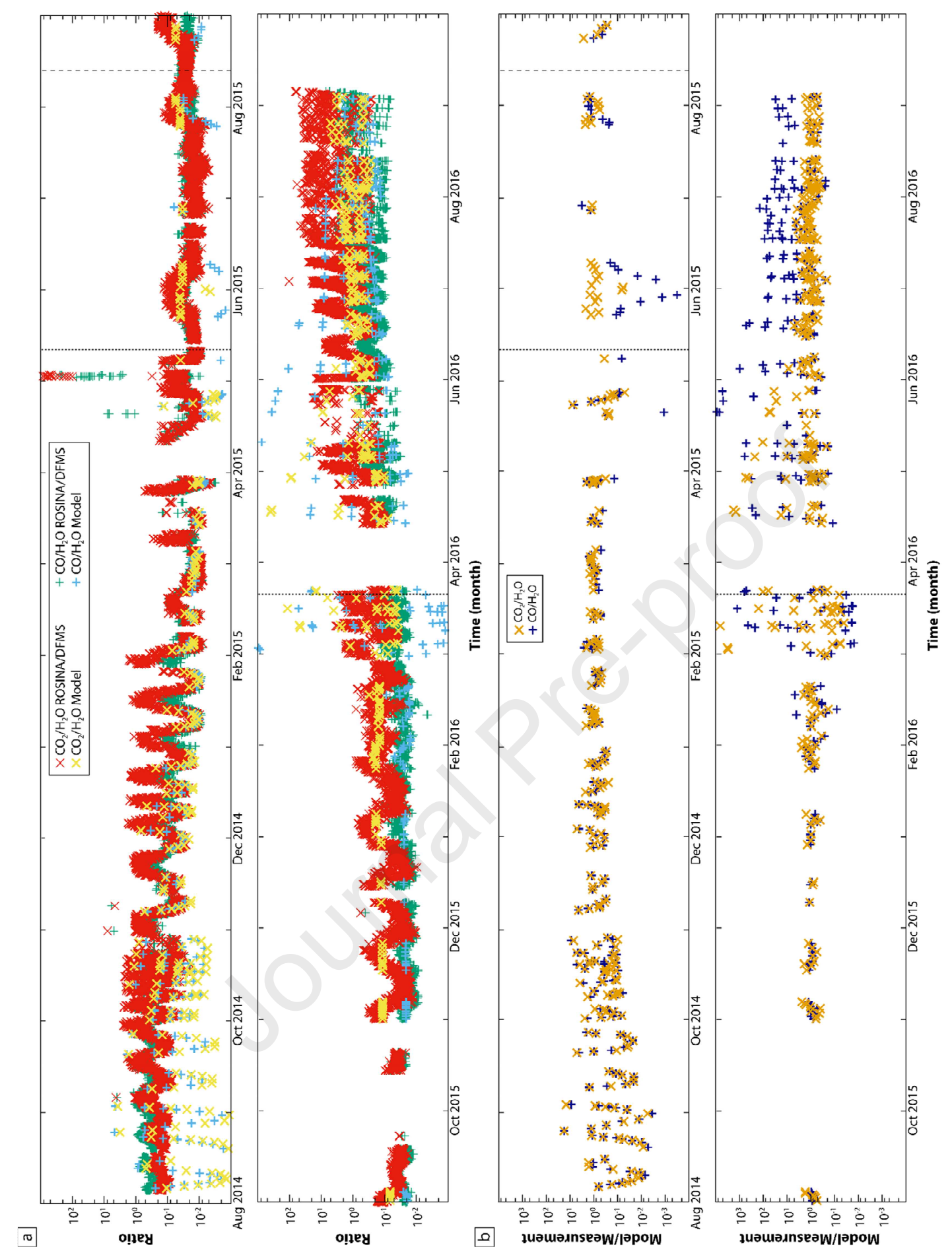

483 Fig. 9: (a) Comparison of $\mathrm{CO} / \mathrm{H}_{2} \mathrm{O}$ and $\mathrm{CO}_{2} / \mathrm{H}_{2} \mathrm{O}$ density ratios computed numerically (blue crosses and yellow crosses, respectively) with the data measured by ROSINA/DFMS (green crosses and red crosses respectively) during the Rosetta mission. The bulk composition and dust mantle thickness set for each month are presented in Section 3.d (Table 2). (b) Ratio of the calculated to the measured density ratios of $\mathrm{CO}_{2} / \mathrm{H}_{2} \mathrm{O}$ and $\mathrm{CO} / \mathrm{H}_{2} \mathrm{O}$ (orange and dark blue crosses respectively) during the Rosetta 
mission. The $1^{\text {st }}$ and $2^{\text {nd }}$ equinoxes are highlighted by vertical black dotted lines and perihelion by vertical black dashed line.

\section{c. Influence of the dust mantle}

A remarkable point is that to get these fits between the model and the ROSINA/DFMS measurements, it is necessary to add a dust mantle at the surface of the nucleus (after it reached steady state without dust mantle) for simulations for periods before the $1^{\text {st }}$ equinox and after the $2^{\text {nd }}$ equinox while it is not necessary for simulations between the equinoxes. If no dust mantle is added for those periods, the order of magnitude remains within the observed range but the trend is no longer consistent with the measurements, particularly for the $\mathrm{CO} / \mathrm{CO}_{2}$ density ratios (Fig. 10).
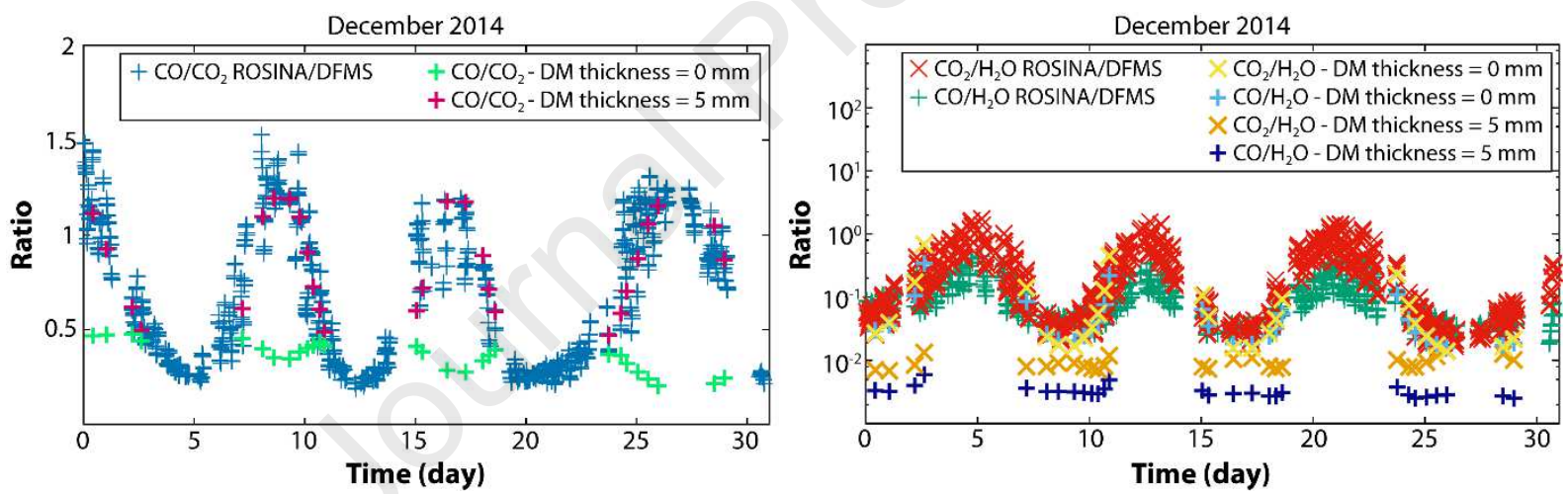

Fig. 10: Comparison of (a) $\mathrm{CO} / \mathrm{CO}_{2}$ and (b) $\mathrm{CO}_{2} / \mathrm{H}_{2} \mathrm{O}$ and $\mathrm{CO} / \mathrm{H}_{2} \mathrm{O}$ density ratios computed by the numerical model without dust mantle $(\mathrm{DM}=0)$ and with dust mantle $(\mathrm{DM}=5 \mathrm{~mm})$ with the data measured by ROSINA/DFMS for December 2014.

The addition of a desiccated dust mantle increases the global thermal inertia. For instance it goes from $\sim 62 \mathrm{~J} \mathrm{~m}^{-2} \mathrm{~K}^{-1} \mathrm{~s}^{-1 / 2}$ without a dust mantle to $\sim 71 \mathrm{~J} \mathrm{~m}^{-2} \mathrm{~K}^{-1} \mathrm{~s}^{-1 / 2}$ with a dust mantle for December 2014. This favours the "storage" of heat and inhibits the immediate reaction of the nucleus surface to solar illumination changes. This increases the thermal lag and the surface temperature affecting heat transfer deeper into the nucleus (Fig. 11). The thermal wave reaches the sublimation fronts of different ices at different times as the sublimation fronts of $\mathrm{CO}_{2}$ and $\mathrm{CO}$ are below the 
511

512

513

514

515

516

517

518

519

520

521

522

523

524

525

526

527

528

529

530

531

surface in this scheme (Fig. 11 and Section 4, Fig. 13). This is contrary to $\mathrm{H}_{2} \mathrm{O}$ which remains close to the surface in all cases. It appears that both, temperature profile and depth of sublimation fronts (Fig. 11) are critical parameters driving $\mathrm{CO}_{2}$ and $\mathrm{CO}$ outgassing pattern. Changes can provoke ratio trend inversion (Figs. 10 and 11). Our results suggest that a limited change in thermal inertia, of about $10 \mathrm{~J}$ $\mathrm{m}^{-2} \mathrm{~K}^{-1} \mathrm{~s}^{-1 / 2}$, has a strong influence on the resulting outgassing pattern.

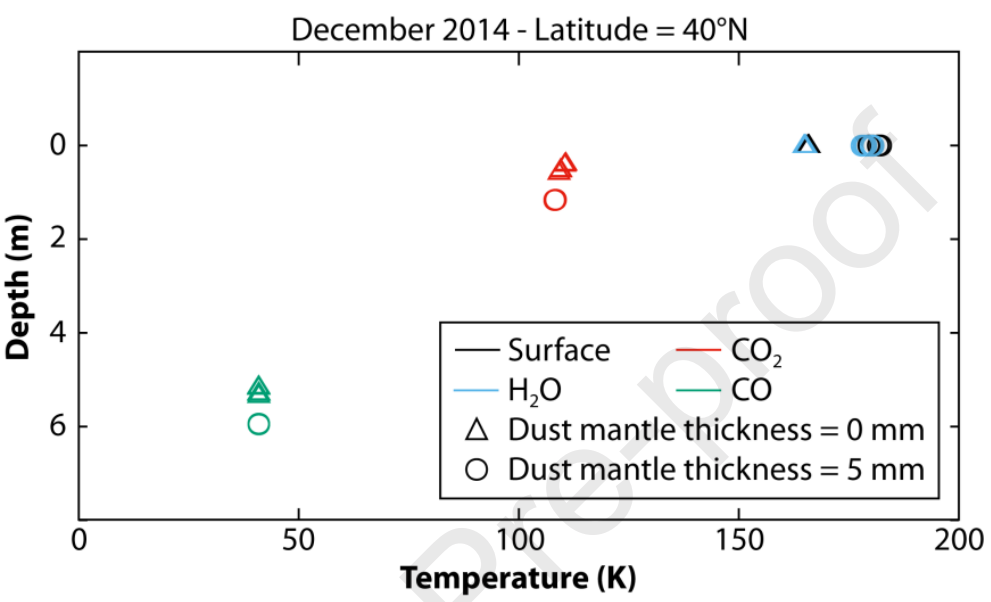

Fig. 11: Depth and temperature of the different sublimation fronts of the volatiles $\left(\mathrm{H}_{2} \mathrm{O}\right.$ : blue, $\mathrm{CO}_{2}$ : red and CO: green) and surface temperature (black) computed by the numerical model without dust mantle (DM $=0$, triangles) and with dust mantle $(\mathrm{DM}=5 \mathrm{~mm}$, circles) for fit obtained for December 2014 (Fig. 10). We take as example results obtained at latitude $40^{\circ} \mathrm{N}$.

d. Nucleus bulk composition and evolution

We are able to reproduce, with good agreement (see Sections 3a and 3b), the ROSINA/DFMS measurements (Figs. 8 and 9 and Table 2). Exceptions are, close to equinoxes and after the $2^{\text {nd }}$ equinox. Numerical results fit the measurements at different latitudes explored by the spacecraft for a given month with a uniform volatile composition. This suggests a rather homogeneous composition of different areas of the nucleus. 


\begin{tabular}{|c|c|c|c|c|c|c|c|c|c|c|c|c|c|}
\hline & $\mathrm{H}_{2} \mathrm{O}$ & $\mathrm{CO}_{2}$ & Co & $\mathrm{CO} / \mathrm{CO}_{2}$ & $\mathrm{CO}_{2} / \mathrm{H}_{2} \mathrm{O}$ & $\mathrm{CO} / \mathrm{H}_{2} \mathrm{O}$ & $\begin{array}{l}\text { thickness } \\
(\mathrm{mm})\end{array}$ & $\mathrm{CO} / \mathrm{CO}_{2}$ & $\mathrm{CO}_{2} / \mathrm{H}_{2} \mathrm{O}$ & $\mathrm{CO} / \mathrm{H}_{2} \mathrm{O}$ & $\mathrm{CO} / \mathrm{CO}_{2}$ & $\mathrm{CO}_{2} / \mathrm{H}_{2} \mathrm{O}$ & $\mathrm{CO} / \mathrm{H}_{2} \mathrm{O}$ \\
\hline Aug-14 & 99.75 & 0.14 & 0.11 & $7.86 \mathrm{E}-01$ & $1.40 \mathrm{E}-03$ & $1.10 \mathrm{E}-03$ & 5 & 1.00 & 1.01 & 0.97 & 5.33E-01 & $5.97 \mathrm{E}-01$ & $9.15 \mathrm{E}-01$ \\
\hline Sep-14 & 99.60 & 0.24 & 0.16 & $6.67 \mathrm{E}-01$ & $2.41 \mathrm{E}-03$ & $1.61 \mathrm{E}-03$ & 5 & 1.03 & 1.17 & 0.90 & 3.61E-01 & $7.86 \mathrm{E}-01$ & $9.19 \mathrm{E}-01$ \\
\hline Oct-14 & 99.00 & 0.70 & 0.30 & $4.29 \mathrm{E}-01$ & 7.07E-03 & 3.03E-03 & 5 & 1.05 & 0.98 & 0.98 & 2.63E-01 & $2.95 \mathrm{E}-01$ & $1.96 \mathrm{E}-01$ \\
\hline Nov-14 & 92.00 & 5.10 & 2.90 & $5.69 \mathrm{E}-01$ & $5.54 \mathrm{E}-02$ & $3.15 \mathrm{E}-02$ & 5 & 0.99 & 1.00 & 0.98 & $1.79 \mathrm{E}-01$ & $1.08 \mathrm{E}-01$ & $9.68 \mathrm{E}-02$ \\
\hline Dec-14 & 93.00 & 4.80 & 2.20 & $4.58 \mathrm{E}-01$ & $5.16 \mathrm{E}-02$ & $2.37 \mathrm{E}-02$ & 5 & 1.04 & 1.08 & 1.00 & $1.98 \mathrm{E}-01$ & $1.32 \mathrm{E}-01$ & $6.38 \mathrm{E}-02$ \\
\hline Jan-15 & 93.00 & 5.00 & 2.00 & $4.00 \mathrm{E}-01$ & $5.38 \mathrm{E}-02$ & $2.15 \mathrm{E}-02$ & 5 & 1.05 & 0.97 & 0.99 & $1.37 \mathrm{E}-01$ & $1.44 \mathrm{E}-02$ & $7.59 \mathrm{E}-03$ \\
\hline Feb-15 & 87.00 & 7.80 & 5.20 & $6.67 \mathrm{E}-01$ & $8.97 \mathrm{E}-02$ & $5.98 \mathrm{E}-02$ & 5 & 0.99 & 1.02 & 1.01 & $2.47 \mathrm{E}-01$ & $9.15 \mathrm{E}-03$ & $7.41 \mathrm{E}-03$ \\
\hline Mar-15 & 89.00 & 6.50 & 4.50 & $6.92 \mathrm{E}-01$ & 7.30E-02 & $5.06 \mathrm{E}-02$ & 5 & 0.97 & 1.04 & 1.03 & 3.33E-01 & $6.74 \mathrm{E}-03$ & $1.11 \mathrm{E}-02$ \\
\hline Apr-15 & 96.00 & 2.20 & 1.80 & $8.18 \mathrm{E}-01$ & 2.29E-02 & $1.88 \mathrm{E}-02$ & 5 & 0.97 & 1.00 & 0.91 & $1.23 \mathrm{E}+02$ & $4.19 \mathrm{E}-02$ & $2.07 \mathrm{E}+00$ \\
\hline May-15 & 89.00 & 3.50 & 7.50 & $2.14 \mathrm{E}+00$ & 3.93E-02 & 8.43E-02 & 0 & 0.05 & 0.97 & 0.04 & $6.98 \mathrm{E}-01$ & 3.41E-02 & $2.87 \mathrm{E}-02$ \\
\hline Jun-15 & 89.00 & 3.00 & 8.00 & $2.67 \mathrm{E}+00$ & $3.37 \mathrm{E}-02$ & $8.99 \mathrm{E}-02$ & 0 & 0.47 & 0.93 & 0.56 & $6.76 \mathrm{E}-01$ & 3.51E-02 & $2.66 \mathrm{E}-02$ \\
\hline Jul-15 & 95.00 & 3.80 & 1.20 & $3.16 \mathrm{E}-01$ & $4.00 \mathrm{E}-02$ & $1.26 \mathrm{E}-02$ & 0 & 1.02 & 1.41 & 0.86 & $4.84 \mathrm{E}-01$ & $2.03 \mathrm{E}-02$ & $9.83 \mathrm{E}-03$ \\
\hline Aug-15 & 94.00 & 5.20 & 0.80 & $1.54 \mathrm{E}-01$ & $5.53 \mathrm{E}-02$ & $8.51 \mathrm{E}-03$ & 0 & 0.99 & 1.17 & 0.96 & $1.93 \mathrm{E}-01$ & $6.32 \mathrm{E}-02$ & $1.17 \mathrm{E}-02$ \\
\hline Sep-15 & 92.00 & 6.20 & 1.80 & $2.90 \mathrm{E}-01$ & $6.74 \mathrm{E}-02$ & $1.96 \mathrm{E}-02$ & 0 & 1.01 & 1.02 & 0.86 & $1.74 \mathrm{E}-01$ & 3.44E-02 & $3.87 \mathrm{E}-03$ \\
\hline Oct-15 & - & - & - & - & - & - & - & - & & - & - & - & - \\
\hline Nov-15 & 87.00 & 11.00 & 2.00 & $1.82 \mathrm{E}-01$ & $1.26 \mathrm{E}-01$ & $2.30 \mathrm{E}-02$ & 0 & 1.04 & 1.08 & 0.97 & $6.31 \mathrm{E}-02$ & 7.42E-02 & $6.05 \mathrm{E}-03$ \\
\hline Dec-15 & 86.00 & 11.80 & 2.20 & $1.86 \mathrm{E}-01$ & $1.37 \mathrm{E}-01$ & $2.56 \mathrm{E}-02$ & 0 & 1.04 & 1.02 & 1.03 & $4.12 \mathrm{E}-02$ & $2.81 \mathrm{E}-02$ & $2.10 \mathrm{E}-03$ \\
\hline Jan-16 & 82.00 & 16.10 & 1.90 & $1.18 \mathrm{E}-01$ & $1.96 \mathrm{E}-01$ & $2.32 \mathrm{E}-02$ & 0 & 0.99 & 1.04 & 0.96 & $5.55 \mathrm{E}-02$ & $1.06 \mathrm{E}-01$ & $1.20 \mathrm{E}-02$ \\
\hline Feb-16 & 86.00 & 12.70 & 1.30 & $1.02 \mathrm{E}-01$ & $1.48 \mathrm{E}-01$ & $1.51 \mathrm{E}-02$ & 0 & 0.99 & 1.00 & 1.00 & $1.20 \mathrm{E}-01$ & $1.92 \mathrm{E}-01$ & $4.84 \mathrm{E}-02$ \\
\hline Mar-16 & 80.00 & 18.00 & 2.00 & $1.11 \mathrm{E}-01$ & $2.25 \mathrm{E}-01$ & $2.50 \mathrm{E}-02$ & 0 & 4.98 & 44.31 & 1018.28 & $5.17 \mathrm{E}-01$ & $1.34 \mathrm{E}+02$ & $2.34 \mathrm{E}+02$ \\
\hline Apr-16 & 98.50 & 1.30 & 0.20 & $1.54 \mathrm{E}-01$ & $1.32 \mathrm{E}-02$ & $2.03 \mathrm{E}-03$ & 5 & 20.92 & 172.84 & 8902.40 & $9.05 \mathrm{E}+00$ & $1.10 \mathrm{E}+02$ & $1.81 \mathrm{E}+03$ \\
\hline May-16 & 97.00 & 2.60 & 0.40 & $1.54 \mathrm{E}-01$ & $2.68 \mathrm{E}-02$ & $4.12 \mathrm{E}-03$ & 5 & 40.41 & 18.21 & 2514.70 & $1.84 \mathrm{E}+01$ & $7.72 \mathrm{E}+00$ & $2.82 \mathrm{E}+02$ \\
\hline Jun-16 & 98.00 & 1.70 & 0.30 & $1.76 \mathrm{E}-01$ & $1.73 \mathrm{E}-02$ & $3.06 \mathrm{E}-03$ & 5 & 15.22 & 1.52 & 53.20 & $9.75 \mathrm{E}+00$ & $6.71 \mathrm{E}-01$ & $1.94 \mathrm{E}+01$ \\
\hline Jul-16 & 98.00 & 1.70 & 0.30 & $1.76 \mathrm{E}-01$ & $1.73 \mathrm{E}-02$ & $3.06 \mathrm{E}-03$ & 5 & 14.59 & 1.40 & 17.60 & $6.86 \mathrm{E}+00$ & $8.68 \mathrm{E}-01$ & $3.81 \mathrm{E}+00$ \\
\hline Aug-16 & 99.00 & 0.96 & 0.04 & $4.17 \mathrm{E}-02$ & $9.70 \mathrm{E}-03$ & $4.04 \mathrm{E}-04$ & 5 & 5.16 & 0.91 & 3.84 & $1.79 \mathrm{E}+00$ & $8.56 \mathrm{E}-01$ & $6.55 \mathrm{E}-01$ \\
\hline Sep-16 & 99.10 & 0.81 & 0.09 & $1.11 \mathrm{E}-01$ & $8.17 \mathrm{E}-03$ & $9.08 \mathrm{E}-04$ & 5 & 7.15 & 1.08 & 9.52 & $2.31 \mathrm{E}+00$ & $1.51 \mathrm{E}+00$ & $1.06 \mathrm{E}+00$ \\
\hline
\end{tabular}

Table 2: Volatiles $\left(\mathrm{H}_{2} \mathrm{O}, \mathrm{CO}_{2}\right.$ and $\left.\mathrm{CO}\right)$ bulk composition of the nucleus used for the numerical

533 modelling to fit the ROSINA/DFMS measurements for each month of the measurements campaign.

534 Molar bulk compositions are expressed in percentage. The thickness (and so its presence or not) of the

535 dust mantle is specified. The likeness between the modelling results and the measurements are

536 evaluated by the calculated density ratio over the measured density ratios (the best match is close to 1)

537 averaged over the respective months and with the root mean square error. Simulation for which the

538 calculated density ratio is different by more than $50 \%$ of the measured density ratio and/or with a

539 RMSE above 1 are considered non reliable and excluded from averaging calculations. Results are

540 plotted in Figure 12. Black horizontal lines separate the months containing inbound or outbound

541 equinoxes and the bold black horizontal lines mark August 2015, the month of perihelion passage.

In order to retrieve the volatiles bulk composition of $67 \mathrm{P} / \mathrm{C}-\mathrm{G}$ nucleus, we averaged the 
545

546

547

548

549

550

551

552

553

554

555

556

557

558

559

560

561

562

563

564

565

566

meeting the required correlation criteria (Section 2.d, Table 2, Fig. 12). We obtained the following volatiles bulk composition for 67P/C-G: $(91.4 \pm 4.5) \%$ of $\mathrm{H}_{2} \mathrm{O},(6.7 \pm 3.5) \%$ of $\mathrm{CO}_{2}$ and $(1.9 \pm 1.2) \%$ of CO. The values obtained are consistent with previous estimation of the volatiles bulk composition of the nucleus (Table 3) from ROSINA/DFMS data pre perihelion (Rubin et al., 2019) and integration over the whole apparition using analytical approaches (Läuter et al., 2019) and Direct Simulation Monte Carlo modelling compared to ROSINA/DFMS data (Combi et al., 2020). However it presents some discrepancy with spectral measurements (Bockelée-Morvan et al., 2016, Biver et al., 2019).

\begin{tabular}{ccccccc} 
& \multicolumn{5}{c}{ Estimation of volatiles bulk composition } \\
\cline { 2 - 6 } Molecule & This study & Rubin et al. (2019) & Läuter et al. (2019) & Combi et al. (2020) & Bockelée-Morvan et al. (2016) & Biver et al. (2019) \\
$\mathrm{H}_{2} \mathrm{O}$ & 100 & 100 & 100 & 100 & \\
$\mathrm{CO}_{2}$ & $7.3 \pm 3.8$ & $4.7 \pm 1.4$ & $5.9 \pm 3.0$ & 7.4 & $14.0-32.0$ & $0.6 \pm 0.1$ \\
$\mathrm{CO}$ & $2.1 \pm 1.3$ & $3.1 \pm 0.9$ & $2.3 \pm 1.0$ & 2.7 &
\end{tabular}

Table 3: Comparison of the estimated bulk compositions of the three main volatiles $\mathrm{H}_{2} \mathrm{O}, \mathrm{CO}_{2}$ and $\mathrm{CO}$ in comet $67 \mathrm{P} / \mathrm{C}-\mathrm{G}$ compared to previous studies based on ROSINA data performed by Rubin et al. (2019), Läuter et al. (2019) and Combi et al. (2020) and on spectral measurements, MIRO and VIRTIS-H, performed by Bockelée-Morvan et al. (2016) and Biver et al. (2019). Molecule abundance is expressed relative to $\mathrm{H}_{2} \mathrm{O}$ abundance.

The nucleus ices compositions and the associated standard deviations of the average bulk composition obtained to fit the ROSINA/DFMS measurements show homogeneity in the sense that they are all displaying a large amount of $\mathrm{H}_{2} \mathrm{O}(>82 \%)$ and $\mathrm{CO}_{2}$ is more abundant than $\mathrm{CO}$. This suggests that, to $1^{\text {st }}$ order, the global composition of the nucleus is rather homogeneous. However, the model also allows us to study volatiles composition at a finer scale. Compositional variability, over the course of the comet's journey around the Sun, has been identified and is highlighted below. 

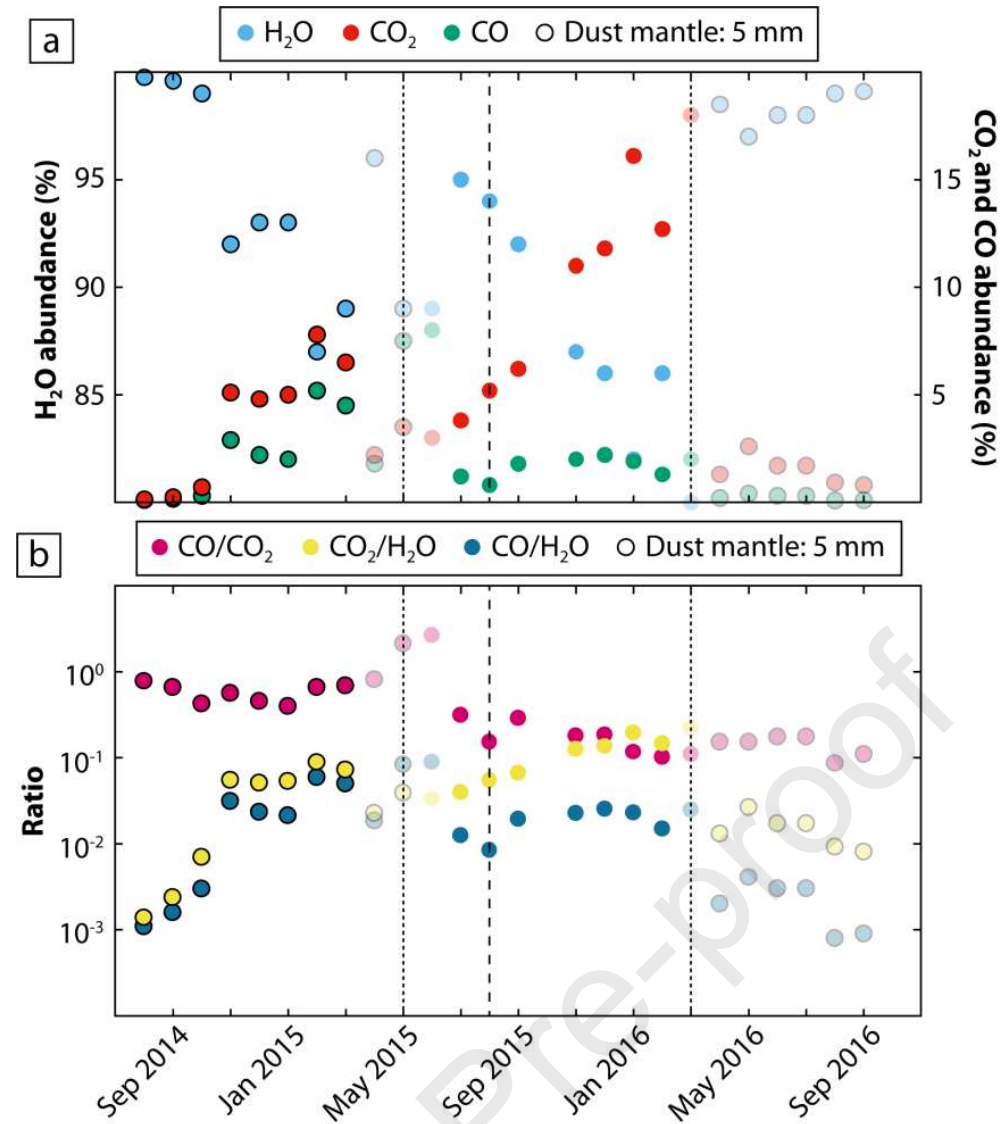

568 Fig. 12: (a) Evolution of the volatile bulk composition $\left(\mathrm{H}_{2} \mathrm{O}, \mathrm{CO}_{2}\right.$ and $\left.\mathrm{CO}\right)$ used for the numerical model to fit the ROSINA/DFMS measurements for each month of the measurements campaign (Table 2). (b) Evolution of the volatiles bulk composition ratios $\left(\mathrm{CO} / \mathrm{CO}_{2}, \mathrm{CO}_{2} / \mathrm{H}_{2} \mathrm{O}\right.$ and $\left.\mathrm{CO} / \mathrm{H}_{2} \mathrm{O}\right)$ for each

571

572

573 month of the measurements campaign (Table 2). The black circles correspond to the presence of a dust mantle $(5 \mathrm{~mm})$ at the surface of the nucleus in the numerical simulation. Data represented with semitransparent colour fit poorly the measurements (Table 2) and should be considered carefully. The $1^{\text {st }}$ and $2^{\text {nd }}$ equinoxes are highlighted by vertical black dotted lines and perihelion by vertical black dashed line.

The volatiles bulk composition used to fit the ROSINA/DFMS measurements suggest 3 distinct patterns: (1) before the $1^{\text {st }}$ equinox, (2) in between the two equinoxes and (3) after the $2^{\text {nd }}$ equinox. Before the $1^{\text {st }}$ equinox the averaged bulk composition is $(94.0 \pm 4.6) \%$ of $\mathrm{H}_{2} \mathrm{O},(3.8 \pm 2.8) \%$ of $\mathrm{CO}_{2}$ and $(2.2 \pm 1.8) \%$ of $\mathrm{CO}$ which is richer in $\mathrm{H}_{2} \mathrm{O}$ and poorer in $\mathrm{CO}_{2}$ than in-between the two equinoxes with an average bulk composition of $(88.9 \pm 4.5) \%$ of $\mathrm{H}_{2} \mathrm{O},(9.5 \pm 4.2) \%$ of $\mathrm{CO}_{2}$ and $(1.6 \pm$ $0.5) \%$ of CO (Table 4). The results after the $2^{\text {nd }}$ equinox give an average bulk composition of $(98.3 \pm$ 
$0.7) \%$ of $\mathrm{H}_{2} \mathrm{O},(1.5 \pm 0.6) \%$ of $\mathrm{CO}_{2}$ and $(0.2 \pm 0.1) \%$ of $\mathrm{CO}$. These last values are given as an indication of the trend but must be taken very carefully as the fits were not fully satisfying the correlation criteria (see Section $3 \mathrm{~b}$ and Table 2), especially the $\mathrm{CO} / \mathrm{H}_{2} \mathrm{O}$ density ratios. The different bulk compositions for these three different periods are enhanced by the values of the $\mathrm{CO} / \mathrm{CO}_{2}$ bulk composition ratios which are, for the given periods, broadly constant through time and with distinctive values (Fig. 12b). Indeed, before the $1^{\text {st }}$ equinox, the average value of $\mathrm{CO} / \mathrm{CO}_{2}$ is about $0.6 \pm 0.1$ and decreases in between the two equinoxes to an average value of about $0.2 \pm 0.1$ (Table 4). The $\mathrm{CO} / \mathrm{CO}_{2}$ bulk composition ratios transition is clear and abrupt at the $1^{\text {st }}$ equinox (Fig. 12b). Changes in the outgassing evolution at the $1^{\text {st }}$ equinox have already been identified by ROSINA analyses (Gasc et al., 2017, Combi et al., 2020). As mentioned above, the value after the $2^{\text {nd }}$ equinox must be taken very carefully but it appears that the $\mathrm{CO} / \mathrm{CO}_{2}$ bulk composition ratio required to reproduce the measurements is about $0.1 \pm 0.1$, which is close to the ratio obtained in-between the two equinoxes.

$\begin{array}{ccccc} & \mathbf{H}_{2} \mathbf{O}(\boldsymbol{\%}) & \mathbf{C O}_{2}(\%) & \mathbf{C O}(\%) & \mathbf{C O} / \mathbf{C O}_{2} \\ \text { Total } & 91.4 \pm 4.5 & 6.7 \pm 3.5 & 1.9 \pm 1.2 & 0.4 \pm 0.1 \\ \text { Before } \mathbf{1}^{\text {st }} \text { equinox } & 94.0 \pm 4.6 & 3.8 \pm 2.8 & 2.2 \pm 1.8 & 0.6 \pm 0.1 \\ \text { In-between equinoxes } & 88.9 \pm 4.5 & 9.5 \pm 4.2 & 1.6 \pm 0.5 & 0.2 \pm 0.1\end{array}$

Table 4: Volatiles bulk composition (in $\% \pm$ standard deviation) of the nucleus obtained with numerical modeling by comparison with ROSINA/DFMS volatiles density measurements. The values correspond of the averaged of the good fits (Table 2) for the respective periods. The data after the $2^{\text {nd }}$ equinox are not included as they poorly fit. The averaged $\mathrm{CO} / \mathrm{CO}_{2}$ bulk composition ratios for the respective periods are also indicated.

Finally, from one month to another, it appears that the different volatiles bulk composition required to fit the measurements evolve through time (Figure 12). The $\mathrm{H}_{2} \mathrm{O}$ percentage is high at the beginning of the measurement campaign in August, September and October 2014 (> 99\%) resulting in $\mathrm{CO}_{2} / \mathrm{H}_{2} \mathrm{O}$ and $\mathrm{CO} / \mathrm{H}_{2} \mathrm{O}$ bulk composition ratios on the order of $1.10^{-3}$ to $1.10^{-2}$. During that period the $\mathrm{CO}_{2} / \mathrm{H}_{2} \mathrm{O}$ and $\mathrm{CO} / \mathrm{H}_{2} \mathrm{O}$ bulk composition ratios increase significantly (from $1.10^{-3}$ to $1.10^{-2}$ ) due to a decrease of the $\mathrm{H}_{2} \mathrm{O}$ abundance while $\mathrm{CO} / \mathrm{CO}_{2}$ experiences a small decrease by a factor less than 2 . 
Then decrease of $\mathrm{H}_{2} \mathrm{O}$ abundance continues until the $1^{\text {st }}$ equinox to values around $88 \%$. We notice a jump of about one order of magnitude of the $\mathrm{CO}_{2} / \mathrm{H}_{2} \mathrm{O}$ and $\mathrm{CO} / \mathrm{H}_{2} \mathrm{O}$ bulk composition ratios between October and September 2014 while $\mathrm{CO} / \mathrm{CO}_{2}$ stays rather constant. After the $1^{\text {st }}$ equinox, the $\mathrm{H}_{2} \mathrm{O}$ abundance is high again (95\%) and then decreases again until the $2^{\text {nd }}$ equinox (about $82 \%$ ). Accordingly, bulk composition ratios $\mathrm{CO}_{2} / \mathrm{H}_{2} \mathrm{O}$ and $\mathrm{CO} / \mathrm{H}_{2} \mathrm{O}$ increase from July 2015 to March 2016 due to the decreases of $\mathrm{H}_{2} \mathrm{O}$ abundance. During that period $\mathrm{CO} / \mathrm{CO}_{2}$ bulk composition ratios experiences a decrease of a factor $\sim 3$.

4. Nucleus internal structure

a. Chemical differentiation

The numerical model computes the equilibrium line between the gas phase and pure ice of each species within the nucleus for a given active point of the nucleus. The nucleus starts from a homogeneous composition and evolves during the revolution around the Sun to a chemically differentiated structure according to the volatility of species and thermal inertia of the nucleus (Fig. 13). The more volatile the species, the deeper is its sublimation interface. The illumination plays an important role in the species differentiation. In the studied case, $\mathrm{H}_{2} \mathrm{O}$ is located at the surface or just below the dust mantle if present. The $\mathrm{CO}_{2}$ sublimation interface is located within the first two meters beneath the surface. Close to perihelion, the $\mathrm{CO}_{2}$ interface is close or even reaches the surface at southern latitudes due to fast erosion. This status remains true for several months. $\mathrm{CO}$ ice is the most volatile of the three studied species and therefore its sublimation interface is deeper $(\sim 5$ metres below the surface at northern latitudes), while at southern latitudes, especially when insolation is strong close to perihelion, the $\mathrm{CO}$ sublimation interface can potentially reach the surface because of the rapid erosion of the surface layer. The addition of a dust mantle at the nucleus surface increases the thermal inertia leading to a deeper differentiation of $\mathrm{CO}_{2}$ and $\mathrm{CO}$ species rather than without a dust mantle. Nevertheless, the low thermal inertia of the nucleus prevents a deeper chemical differentiation. 
a

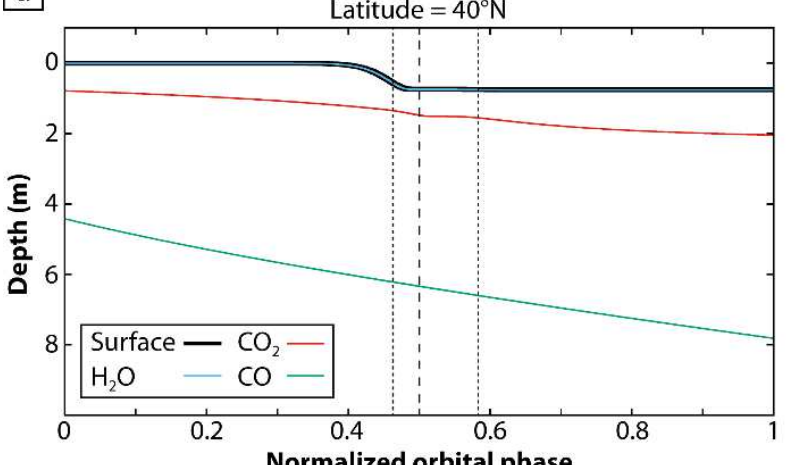

$\mathrm{b}$

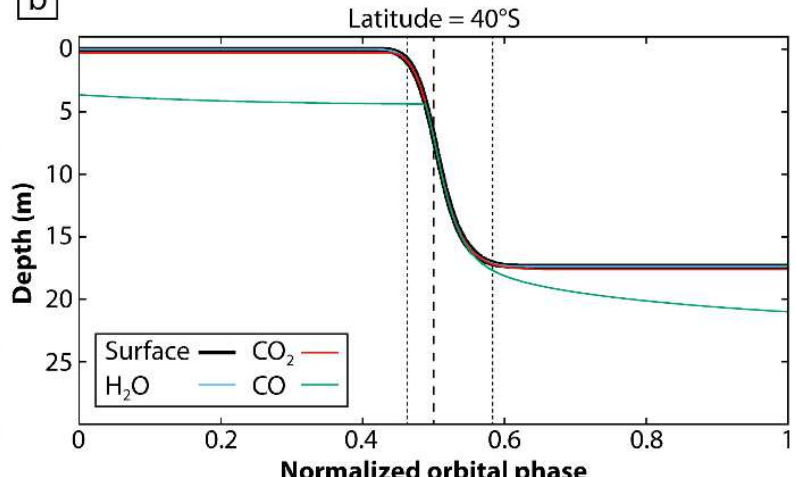

637

Fig. 13: Modelled internal structure of the nucleus of $67 \mathrm{P} / \mathrm{C}-\mathrm{G}$ at (a) latitudes $40^{\circ} \mathrm{N}$ (December 2014) and (b) $40^{\circ} \mathrm{S}$ (November 2015 ) over one orbital period ( $\sim 6.44 \mathrm{yrs)}$ ). The perihelion is highlighted by the black dashed line and equinoxes by the pointed black lines.

Spectral signatures of $\mathrm{H}_{2} \mathrm{O}$ ice have been detected at several locations on the surface of $67 \mathrm{P} / \mathrm{C}$ G nucleus (Pommerol et al., 2015, Groussin et al., 2015, Fornasier et al., 2016). Bright $\mathrm{H}_{2} \mathrm{O}$ ice spots are mainly observed near collapsing cliffs, dislocated boulders, and dust layered scarps. Therefore ice is present in the upper layers of the comet and can persist for several weeks but there is no wide presence of pure $\mathrm{H}_{2} \mathrm{O}$ ice at the nucleus surface. Through perihelion, Fornasier et al. (2016) observed a change in colour towards blue suggesting an increase in the presence of water ice on the nucleus surface during this period. Spectral detection of $\mathrm{CO}_{2}$ ice has been recorded in the southern hemisphere region, Anhur (Filacchione et al., 2016). However, authors suggested that $\mathrm{CO}_{2}$ formed by recondensation of $\mathrm{CO}_{2}$ gas at the surface due to extreme changes of illumination conditions. The presence of $\mathrm{CO}_{2}$ front deeper than $\mathrm{H}_{2} \mathrm{O}$ is consistent with previous interpretation (Bockélée-Morvan et al., 2016, Capria et al., 2017, Biver et al., 2019). No CO spectral signature has been observed at the surface of the nucleus.

\section{b. Surface erosion}

The nucleus experiences surface erosion as the ices sublimate and the dust grains are released. We assume the comet surface displays an EAF of 20\% (Section 2.d). At each orbit, for an given point active at the nucleus surface computed by the thermo-physical model, the $\mathrm{H}_{2} \mathrm{O}$ outgassing provokes a 
surface ablation of less than $1 \mathrm{~m}$ at $40^{\circ} \mathrm{N}$ latitude (with a dust mantle) and about 17 metres at $40^{\circ} \mathrm{S}$ latitude (without dust mantle) (Fig. 13). Our computed erosion estimation for the northern hemisphere is broadly consistent with previous calculations from thermo-physical model (taking into account the nucleus shape and only $\mathrm{H}_{2} \mathrm{O}$ ice) with the presence of a millimetre thick desiccated layer at the top predicting less than $1 \mathrm{~m}$ of erosion (Keller et al., 2015b). Our estimation of the southern hemisphere erosion tends to be greater than this same model without desiccated layer at the top with only few meters of ablation, even so the maximum erosion capability of the thermo-physical model developed by Keller et al., 2015b can locally reach $20 \mathrm{~m}$. However, the authors acknowledged the overestimation of $\mathrm{H}_{2} \mathrm{O}$ ice sublimation as they considered a fully active surface leading to a $\mathrm{H}_{2} \mathrm{O}$ production about 10 times higher compared to observation. In addition, ablation values computed by our thermo-physical model are larger than estimated based on the total mass loss of the nucleus with ablation of $0.2 \mathrm{~m}$ and $0.8 \mathrm{~m}$ respectively for northern and southern hemispheres (Pätzold Rosetta SWT 47, Keller et al., 2017). Finally, OSIRIS observations, before and after perihelion, reveal that the nucleus does not experience a global erosion of meters-scale (El-Maary et al., 2017). If so, the nucleus shape modification would have been identified at the OSIRIS pixel resolution which is up to tens of centimetres. However, locally, morphological changes and erosion have been identified in particular with dust redistribution, cliffs collapses and boulders movements (Groussin et al. 2015, Hu et al. 2017, El-Maary et al., 2017). The mass loss can reach in places up to $14 \mathrm{~m}$ as estimated by Fornasier et al., (2019) in the Anhur region located in the southern hemisphere.

The erosion values computed by our thermo-physical model are likely to be overestimated as the $\mathrm{H}_{2} \mathrm{O}$ outgassing is overestimated, especially in the southern hemisphere (Fig. 3). The overestimation of the erosion might come from our numerical assumption. The considered spherical nucleus neglects the influence of shadows on the global solar input energy. However, 67P/C-G displays a complex shape (Preusker et al., 2015; Jorda el al., 2016), provoking strong shadowing effect that influence the input energy (Keller et al., 2015b). The absence of shadows leads to an enhanced volatiles production in our model. In addition, we allow the presence of ices up to the nucleus surface that will also enhance the outgassing (especially $\mathrm{H}_{2} \mathrm{O}$, Fig. 13). These effects are of particular 
688

689

690

691

692

693

694

695

696

697

698

699

700

701

702

703

704

705

706

707

708

709

710

711

712

importance in the southern hemisphere where the energy input is stronger than in the northern hemisphere (Keller et al., 2015b) and no substantial dust layer covers the surface. This effect is modulated for our results in the northern hemisphere as a dust mantle at the nucleus surface is present, lowering the erosion (Fig. 13). Therefore, the erosion values provided by the thermo-physical model are obtained for specific assumptions and can be applied only locally for the comet 67P/C-G. Due to the likely overestimation of surface erosion, the obtained values can be considered as an upper limit of the erosion rate at the surface of the comet $67 \mathrm{P} / \mathrm{C}-\mathrm{G}$.

\section{c. Porosity}

Porosity, initially set as a constant input parameter (Table 1), can evolve as the comet orbits around the Sun and experiences higher temperatures and ice phase changes. Within the model, condensation in the pore space of the nucleus can lead to changes in porosity. For both presented cases in Figure 14, simulations at northern and southern latitudes (and with or without dust mantle respectively at the surface of the nucleus), porosity profiles varied mainly within the $1^{\text {st }}$ meter below the surface. Just below the surface, the porosity decreases by between $5 \%$ and $11 \%$ compared to the initial porosity leading to a "hard" thin (about few centimetres) layer. Additional peaks, weaker and broader, occur below in both cases. For the southern hemisphere a second peak occurs about $10 \mathrm{~cm}$ below the surface and for the northern hemisphere one occurs about $1 \mathrm{~m}$ and a second one deeper at about $5 \mathrm{~m}$. Below the deepest peak the porosity retains its initial value. Unsurprisingly, the porosity minima are correlated with the sublimation front of each species as they are located at similar depths (Fig. 13). Therefore each species interface leads to a porosity anomaly. Only two peaks are observed for the southern latitude case because the $\mathrm{H}_{2} \mathrm{O}$ and $\mathrm{CO}_{2}$ interfaces are close to each other at perihelion for which porosity profiles have been computed. 


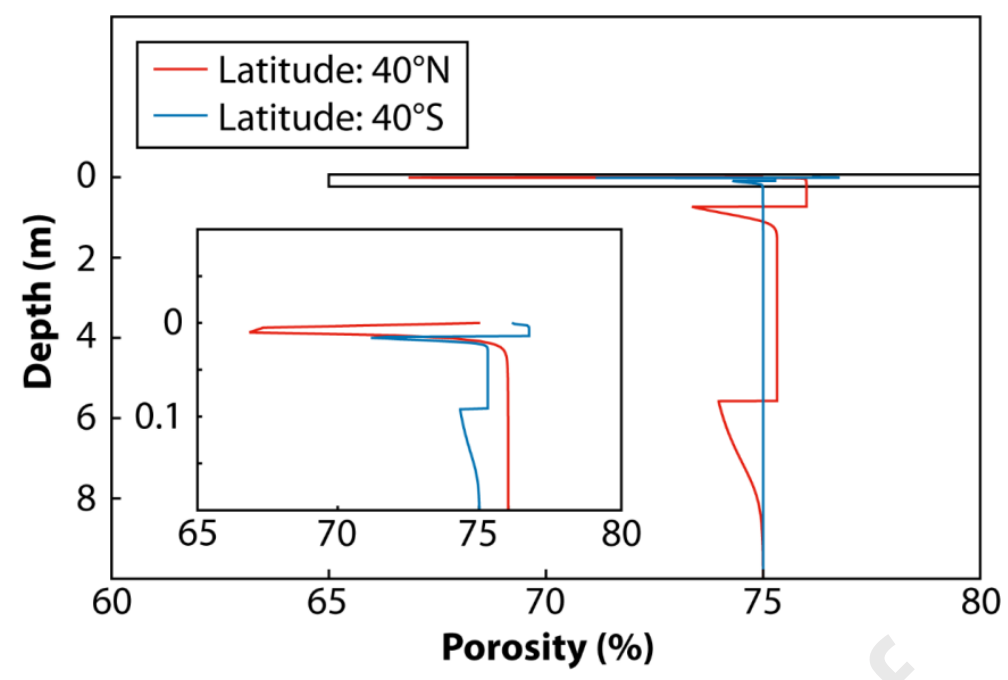

714

715

The variation of porosity is consistent with numerical models (Kossacki et al., 2015, Attree et al., 2017), laboratory experiments (Kochan et al., 1989, Poch et al., 2016), geomorphologic observations of 67P/C-G (Auger et al., 2017) and in-situ measurements performed by Rosetta's lander Philae in the Abydos region (Spohn et al., 2015, Knapmeyer et al., 2018). The results either predict or have measured a hardened layer within the first centimetres and up to 1 meter below the surface of the nucleus. Re-condensation of the gas phase present in the pore of the nucleus and sintering effects create bonds between the ice grains that form a "hard" layer in the sub-surface. At Philae's landing site, the MUPUS instrument was not able to drill into the nucleus material. It was suggested that the instrument encountered a hard layer within the first centimetres below the surface. The porosity of this "hard" layer on 67P/C-G was estimated to be between $30 \%$ and $65 \%$ depending upon the nature of the refractory material (Spohn et al., 2015). However, these values are lower than the ones computed with our numerical model (Fig. 14).
5. Interpretation and discussion 
The thermo-physical model is able to reproduce several volatiles density measurements of

737

738

739

ROSINA/DFMS in the coma with a given volatiles bulk composition of the nucleus for different latitudes explored during a given month. In addition, the bulk composition of the nucleus presents some homogeneity (Section 3.d and Figs. 12 and 15 and Table 2). Both observations suggest that, to $1^{\text {st }}$ order, the chemical outgassing pattern is mainly insolation driven rather than due to strong chemical heterogeneities. This is consistent with previous studies (De Sanctis et al., 2010, Fougere et al., 2016, Schroeder et al., 2019). The thermo-physical model is 1D and does not take into account the complex shape of the nucleus but the model would suggest that the heterogeneities detected in the coma composition (Hässig et al., 2015) are mainly driven by the tilt of the rotation axis and the comet's eccentric orbit (Table 1).

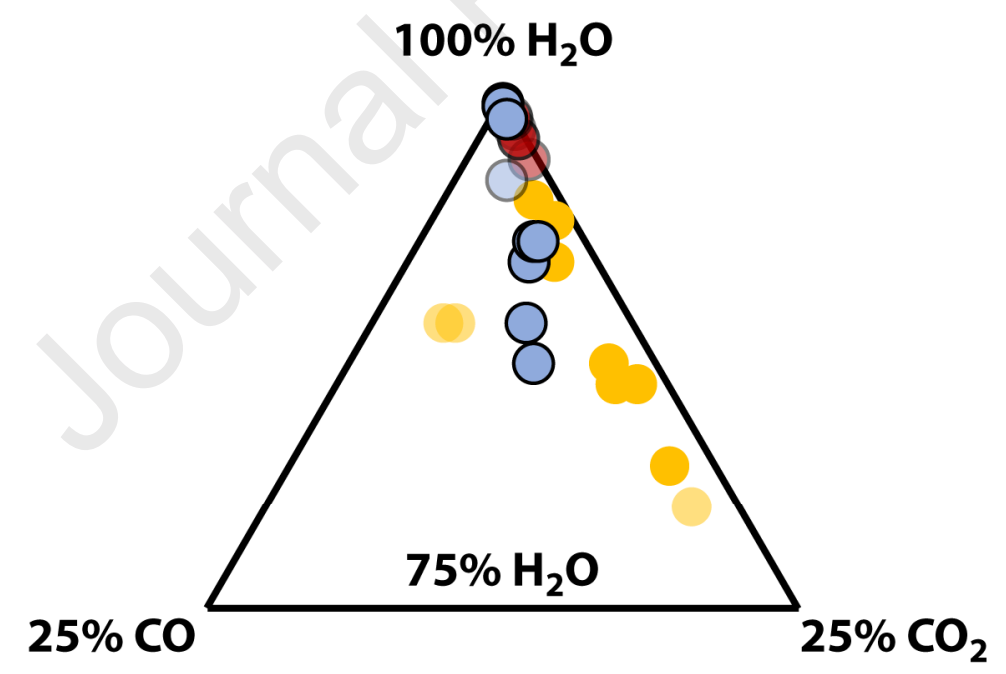

Nucleus volatiles composition:

Before $1^{\text {st }}$ equinox

Between $1^{\text {st }}$ and $2^{\text {nd }}$ equinoxes

After $2^{\text {nd }}$ equinox

Dust mantle:

Fig. 15: Ternary diagram of volatiles species $\left(\mathrm{H}_{2} \mathrm{O}, \mathrm{CO}_{2}\right.$ and $\left.\mathrm{CO}\right)$ bulk composition required to fit ROSINA/DFMS volatiles density measurements. Distinction between data before the $1^{\text {st }}$ equinox (blue circles), in between the two equinoxes (yellow circles) and after the $2^{\text {nd }}$ equinox (red circles) are 
highlighted. Data represented with light colour fit poorly the measurements (Table 2) and should be considered carefully. The presence of a dust mantle (black circle) is also specified.
b. Dichotomy

Although our results show that the nucleus displays to $1^{\text {st }}$ order homogeneity in the volatile bulk composition, it also reveals a dichotomy in composition between the period before the $1^{\text {st }}$ equinox and the period in between the two equinoxes (Figs. 12 and 15 and Table 2) that influence the ROSINA/DFMS volatiles density measurements. The dichotomy is mainly highlighted by the averaged value of the $\mathrm{CO} / \mathrm{CO}_{2}$ bulk composition ratios before the $1^{\text {st }}$ equinox $(0.6 \pm 0.1)$ and inbetween the two equinoxes $(0.2 \pm 0.1)$. This discrepancy could either reflect a change of physical properties at the surface during the $1^{\text {st }}$ equinox or a difference in bulk composition between the northern and southern hemispheres. The later hypothesis is favoured as the northern latitudes are rather exposed to illumination before the $1^{\text {st }}$ equinox and after the $2^{\text {nd }}$ equinox while the southern latitudes are rather exposed in-between equinoxes (Keller et al. 2015b, Fig. 4). The volatiles bulk composition computed before the $1^{\text {st }}$ equinox and in-between equinoxes reflect the contribution to the outgassing pattern of the northern and southern hemisphere respectively (Fig. 16). Therefore, the southern hemisphere appears to be less depleted in highly volatile species as chemical differentiation is less deep below the surface in the South (Fig. 13). This dichotomy has been noted as well by Hoang et al. (2019). As perihelion occurs between the two equinoxes, the North experienced a long and "cold" summer while the South experienced a short and "warm" summer that could result in altered volatile bulk compositions. However, we are not able to reproduce this behaviour with the numerical model as the bulk composition of volatiles in the nucleus at the end of the simulation $\left(5^{\text {th }}\right.$ orbit $)$ is similar to the initial composition set. Additional investigations should be performed to study the long term evolution of the volatiles bulk composition of the northern and southern latitudes. 


\section{- $\mathrm{CO} / \mathrm{CO}_{2} \odot \mathrm{CO}_{2} / \mathrm{H}_{2} \mathrm{O} \bullet \mathrm{CO} / \mathrm{H}_{2} \mathrm{O}$ O Dust mantle: $5 \mathrm{~mm}$}

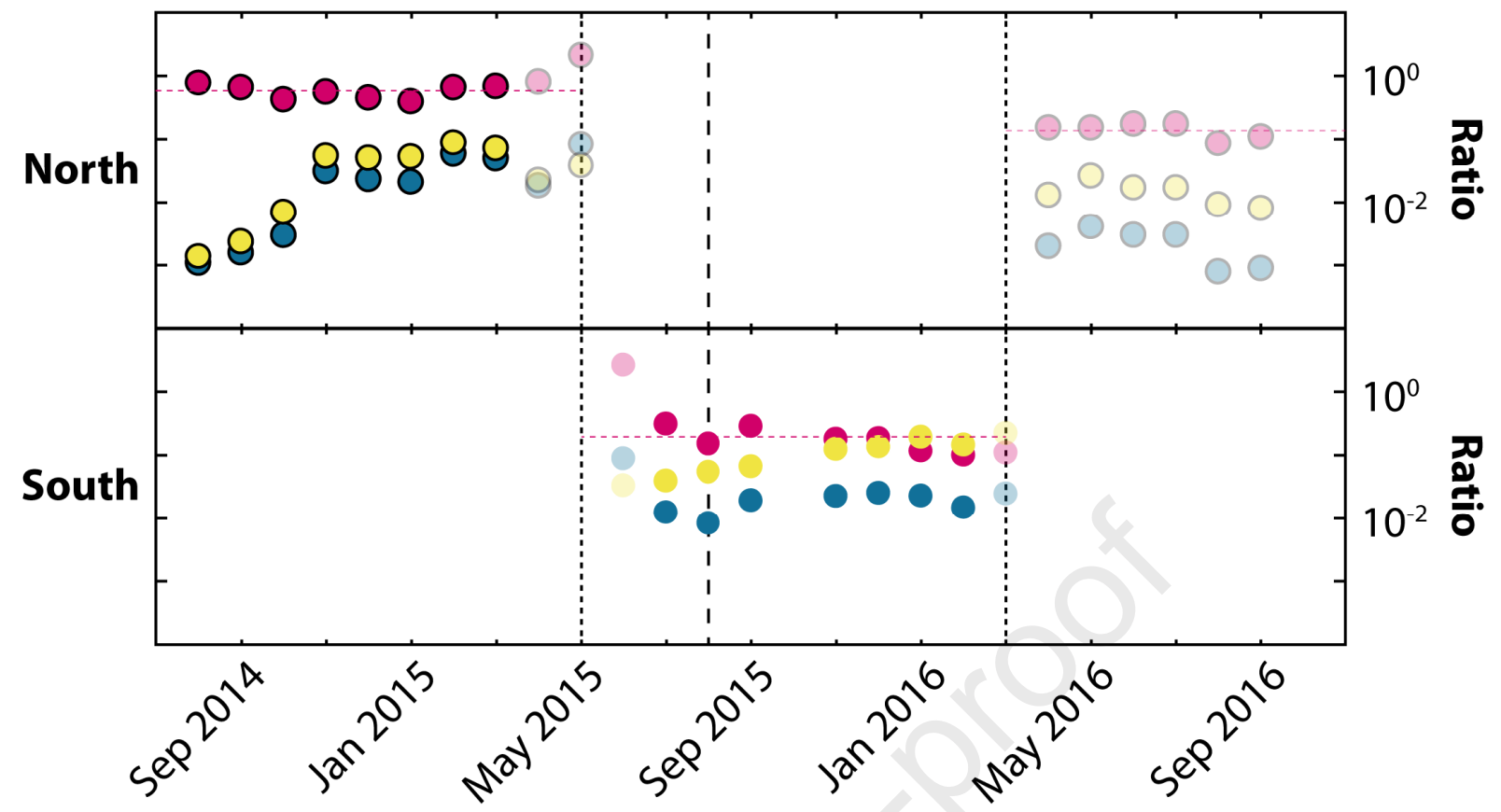

Fig. 16: Evolution of the volatiles bulk composition ratios $\left(\mathrm{CO} / \mathrm{CO}_{2}, \mathrm{CO}_{2} / \mathrm{H}_{2} \mathrm{O}\right.$ and $\left.\mathrm{CO} / \mathrm{H}_{2} \mathrm{O}\right)$ of the nucleus for each month of the measurements campaign (Table 2) and as function of nucleus hemisphere. Discrimination of the data between North and South has been obtained from the sampling strategy described in Section 2.d. This excludes southern latitudes before $1^{\text {st }}$ equinox and after $2^{\text {nd }}$ equinox and northern latitude in between equinoxes as results are obtained for incidence angle above $90^{\circ}$ (Fig. 4). The horizontal pink dashed lines indicate the average values of the $\mathrm{CO} / \mathrm{CO}_{2}$ bulk composition ratio for a given period. The black circles correspond to the presence of a dust mantle (5 $\mathrm{mm})$ at the surface of the nucleus in the numerical simulation. Data represented with light colour fit poorly the measurements (Table 2 ) and should be considered carefully. The $1^{\text {st }}$ and $2^{\text {nd }}$ equinoxes are highlighted by vertical black dotted lines and perihelion by vertical black dashed line.

To fit the data before the $1^{\text {st }}$ equinox, it is necessary to modify the time lag of the thermal wave propagation through the nucleus interior to reproduce the volatiles outgassing pattern acquired by ROSINA/DFMS. In our model, this is done by the addition of a desiccated dust layer at the surface at the beginning of the selected orbit. Although we acknowledge that other physical parameters could potentially have a similar effect on the temperature profile and need to be explored (Section 5.f), the addition of the dust mantle is consistent with surface observations. During the pre- $1^{\text {st }}$ equinox phase, 
illuminated areas of the comet are mainly located in the northern hemisphere where the presence of a dust mantle at the surface has been observed and is dominated by back falling particles (Thomas et al., 2015a and 2015b; Keller et al., 2015b) while southern areas, more exposed to the Sun between the two equinoxes, exhibit more dust-free surfaces. The dust mantle has been observed to be eroded by outgassing and restored by dust particle transport and back falling (Groussin et al., 2015, Fornasier et al., 2016, Hu et al., 2017) at the surface of the nucleus through perihelion passage. Thus, these changes will provoke disturbance of the heat wave propagation trough the interior from one orbit to another, influencing the outgassing pattern. The presence of the dust mantle also affects the depletion in volatiles enhancing the compositional dichotomy and contributes to the morphology differences between the northern and southern hemispheres (Keller et al., 2015b, 2017, El-Maarry et al., 2016).

c. Discrepancy at equinoxes and after the $2^{\text {nd }}$ equinox

After the $2^{\text {nd }}$ equinox, the thermo-physical model fits sometimes $\mathrm{CO}_{2} / \mathrm{H}_{2} \mathrm{O}$ density ratios but poorly $\mathrm{CO} / \mathrm{CO}_{2}$ and $\mathrm{CO} / \mathrm{H}_{2} \mathrm{O}$ density ratios (Table 2, Figs. 8 and 9). In this period, only the northern latitudes values are sampled by the thermo-physical model because of incidence angle constraint (Fig. 4). As for the period before the $1^{\text {st }}$ equinox, a dust mantle is required to reproduce the trend of $\mathrm{CO}_{2} / \mathrm{H}_{2} \mathrm{O}$ density ratios. Even so, the values have to be taken carefully due to the low correlation values (Table 2). The averaged $\mathrm{CO} / \mathrm{CO}_{2}$ bulk composition ratio value $(0.1 \pm 0.1)$ required to get close to the measurements is closer to the ones in between the two equinoxes $(0.2 \pm 0.1)$ for which southern regions were illuminated. So it appears that the outgassing behavior after the $2^{\text {nd }}$ equinox is a mixture between the southern and northern hemisphere contribution. We interpret this as the fact that the outgassing signature of the southern plains is dominating the ROSINA/DFMS measurements from the $2^{\text {nd }}$ equinox until the end of the Rosetta mission and non-radial outgassing become important (Läuter et al., 2019). It affects in particular CO. Because of its volatility, these species is mostly present several meters below the surface and thus less affected by direct surface illumination variation but rather driven by thermal inertia (Fig. 13). Outgassing of $\mathrm{CO}_{2}$ has been observed in areas that were nonilluminated (Bockélée-Morvan et al., 2016). Although the thermal inertia of the comet is low, it has an 
823

824

825

826

827

828

829

830

831

832

833

834

835

836

837

838

839

840

841

842

843

844

845

846

847

848

849

850

influence on the outgassing pattern and should not be neglected when interpreting the outgassing behavior of 67P/C-G. We can also notice that toward the end of the mission the fits improve with values of the calculated density ratio over the measured density ratio getting closer to 1 and the decrease of the RMSE (Figs. 8 and 7, Table 2). That might translate the weakened of the southern regions in the outgassing contribution.

Similarly, to explain the poor fit around the $1^{\text {st }}$ equinox (Table 2), we assume that this "contamination" affects measurements while the illumination moves from the northern hemisphere toward the southern hemisphere (Fig. 4). The effect might be less profound because the northern hemisphere has not experienced the intense illumination associated with perihelion.

d. Volatile evolution

The observed evolution of the volatiles through time can be significant as for instance the jump observed of the $\mathrm{CO}_{2} / \mathrm{H}_{2} \mathrm{O}$ and $\mathrm{CO} / \mathrm{H}_{2} \mathrm{O}$ bulk composition ratios in between October 2014 and November 2014 (Section 3d, Fig. 12). It might be due to several hypotheses that need to be investigated in the future. A first hypothesis could be that while an area starts to be illuminated, not only the volatiles species present in the nucleus start to sublimate but also the gases that have recondensed at the surface/sub-surface in case of a drastic temperature change. Numerical calculations have estimated that the back-flux can represent up to few percent of the total outgassing (Rubin et al. 2014, Liao et al. 2018). The condensation of gases at the surface can lead to the deposition of micrometres thickness frost layer (Liao et al. 2018) that is consistent with Rosetta observation. For instance, spectral measurements suggest of a $\mathrm{H}_{2} \mathrm{O}$ frost cycle (De Sanctis et al., 2015, Filacchionne et al., 2020) and the presence of potential $\mathrm{CO}_{2}$ frost (Filacchionne et al., 2016). Frost may potentially condensed and be preserved on both northern and southern hemispheres followed by sublimation as it comes closer to the Sun. We speculate that this could explain the decrease of $\mathrm{H}_{2} \mathrm{O}$ abundance, once for periods before the $1^{\text {st }}$ equinox and once for periods in between the two equinoxes due to the sublimation of frost. This effect would be less important for $\mathrm{CO}_{2}$ or $\mathrm{CO}$ as the bulk composition ratios $\mathrm{CO} / \mathrm{CO}_{2}$ are broadly constant for the respective periods. Presence of $\mathrm{H}_{2} \mathrm{O}$ ice has also been detected in 
the dust mantle (Groussin et al., 2015, Fornasier et al., 2016) and could influence the outgassing of the northern plains as well. A second hypothesis could be related to the evolution of physical parameters such as local dust mantle thickness. The dust mantle prevents $\mathrm{H}_{2} \mathrm{O}$ from sublimating but on 67P/C-G it has been observed to be eroded/shaded due to gas activity revealing $\mathrm{H}_{2} \mathrm{O}$ water ice signatures (Groussin et al., 2015, Fornasier et al., 2016, Hu et al., 2017). Therefore we speculate that the decrease of $\mathrm{H}_{2} \mathrm{O}$ abundance may be an artefact due to the actual thinning of the dust mantle itself by affecting the $\mathrm{H}_{2} \mathrm{O}$ outgassing. However, it should not/less affect the southern plains.

e. Internal heterogeneities

Our numerical simulations start with a homogeneous nucleus that then evolves as it orbits the Sun. Our results revealed that the outgassing pattern of the coma is mainly driven by insolation with no strong heterogeneities in the nucleus composition. It suggests that the initial material forming the 67P/C-G nucleus might have potentially been chemically homogeneous. However, our results cannot rule out the possibility that there was at least some minor degree of heterogeneity. The North-South dichotomy may have developed before the nucleus reached its current rotation axis inclination. We are unable to reproduce this evolution from a single homogenous initial bulk composition of the nucleus in the current orbit. The potential initial homogeneity of the nucleus might be strengthened by the fact the numerical model do not detect differences (with non-averaged results, Fig. 7a) of density ratio $\mathrm{CO} / \mathrm{CO}_{2}$ between the two lobes of the comet for different sub-spacecraft position during a given month. The bi-lobate shape of 67P/C-G nucleus is may be the result of a low velocity impact between two objects (Massironi et al., 2015). The North and South hemispheres include both these lobes but we only detect a North-South dichotomy. Thus the two lobes might have similar initial bulk composition (as suggested by Schroeder et al. (2019) looking at the D/H ratio in the water of the two lobes) and have then evolved accordingly.

Vertical chemical heterogeneities of the nucleus form as the sublimation interface of ices receded when the nucleus comes to the inner solar system and is illuminated by the Sun. As shown in Figure 13, the first meters below the surface in the North and in the South are experiencing chemical 
differentiation leading to a "layered" structure of the nucleus according to the volatility of the ices (Prialnik et al., 2004, De Sanctis et al., 2010, Marboeuf et al., 2014, Fougere et al., 2016, Capria et al. 2017). In this study, we only investigate three species, but more volatile species will lead to a deeper differentiation. Below the deeper sublimation interface we expect that the cometary material is pristine unless other physical effects have been at work.

Lateral chemical heterogeneities at the same radius are created by different surface illumination. The complex shape of the nucleus in addition to the tilt of the rotation axis lead to different illumination that drives variations of the ice sublimation rate through time for adjacent regions leading to horizontal chemical heterogeneities (Guilbert-Lepoutre et al., 2016). In addition, the lateral heterogeneities will also be controlled by the repartition of active areas taking into account in the EAF parameter (Marschall et al. 2020b). Interaction of both parameters might lead to the formation of different sub-surface structures.

As for chemical heterogeneities, physical heterogeneities can form the same way. For instance sublimation/condensation of volatiles lead to grain and porosity evolution (Fig. 14) which in turn will affect the thermal properties of layers and the outgassing (Kossacki and Czwechowski 2019). In addition, release of dust particles by sublimation and transport and deposition of dust particles from the South to the North (Keller et al., 2015b) build a dust mantle with various thicknesses that will affect the properties of the nucleus.

The presence of local chemical and physical heterogeneities could explain the morphological diversity observed at the surface of the comet (Thomas et al., 2015a).

\section{f. Physical properties sensitivity}

Besides the potential source of error stated in Section 2c, uncertainty in the physical properties of the nucleus (Table 1) can potentially affect the outgassing pattern and lead to discrepancies between the measurements and the numerical results. An example is the dust properties. In the thermo-physical model we estimated the dust mantle to be millimetres thick, whereas the dust mantle thickness is variable and may reach several metres locally (Thomas et al., 2015b). This estimation of dust mantle 
thickness might therefore reflect an average dust thickness at the surface of the nucleus where activity is most profound. Another influence could be that the intrinsic parameters set for the dust are not optimized. Indeed, we used parameters for silicate dust but the dust composition is complex and difficult to constrain with a significant contribution of organics components (Quirico et al., 2016, Bardyn et al. 2017). It further influences the physical properties of the dust affecting the density, thermal conductivity, and heat capacity of the surface layer. In our model the dust particles are modelled as spheres but observed and collected particles (by COSIMA and GIADA) present various morphologies with sometimes a high porosity inferring low particle density $<1500 \mathrm{~kg} \mathrm{~m}^{-3}$ (Fulle et al., 2017, Merouane et al. 2017). Even though the model cannot take into account complex dust shapes, a size-dependant density law could be used to evaluate the influence of the particle density on the outgassing (Merouane et al. 2017). In the same way, the dust-to-ice mass ratio value is quite debated (Choukroun et al., 2020) and can potentially affect the outgassing pattern.

Further exploration of the range of the different free parameters would help to get towards a more realistic model and estimation of the characteristics of the 67P/C-G nucleus. Variation of parameters value might have a similar effect to the addition of a dust mantle highlighted in this study (Section 3.c) or improve the fits. This would be interesting in particular to improve the fit of $\mathrm{CO}_{2} / \mathrm{H}_{2} \mathrm{O}$ and $\mathrm{CO} / \mathrm{H}_{2} \mathrm{O}$ density ratios for the simulations performed at the beginning of the mission (August to October 2014) as, even if the results match our correlation criteria (Section 2.d), the RMSE values are significantly higher and closer to our threshold value of 1 ( 0.58 for $\mathrm{CO}_{2} / \mathrm{H}_{2} \mathrm{O}$ and $0.68 \mathrm{CO} / \mathrm{H}_{2} \mathrm{O}$ averaged for the 3 first months $)$ than the ones obtained for other months $\left(0.07\right.$ for $\mathrm{CO}_{2} / \mathrm{H}_{2} \mathrm{O}$ and 0.02 $\mathrm{CO} / \mathrm{H}_{2} \mathrm{O}$ averaged for the remaining month that have match our correlation criteria). For instance, modifying parameters values could help to minimize the variation in amplitude (Fig. 9) and might influence the volatiles abundances. Similarly, the estimated erosion performed by the thermo-physical model appears to be larger than the observation (Section 4.a). In the South the erosion is so strong that it could potentially expose both $\mathrm{CO}_{2}$ and $\mathrm{CO}$ ice for several months (Fig. 13) but those ice exposures were not detected during Rosetta mission. Finally, the thermo-physical model tends to underestimate the porosity range in the $1^{\text {st }}$ meter of the nucleus. That can be explained by several parameters such as (1) incorrect characteristics of the refractory material (dust mantle thickness, dust-to-ice mass ratio, 
935

936

937

938

939

940

941

942

943

944

945

946

947

948

949

950

951

952

953

954

955

956

957

958

959

960

961

962

dust conductivity and heat capacity...) influencing the thermal inertia, (2) the grains and pore sizes and/or (3) the non-implementation of the sintering process between the grains in the numerical model that can lead to an underestimation of the layer hardening.

g. Benefit of the thermo-physical model compared to previous studies

Our results have shown a good agreement with previous studies that have either directly integrated the bulk loss of volatiles measured by ROSINA/DFMS measurements (Rubin et al., 2019) or performed a model inversion of the ROSINA/DFMS measurements (Combi et al., 2020, Läuter et al., 2019). Comparison to spectral measurements (Bockelée-Morvan et al., 2016, Biver et al., 2019) show larger discrepancies, especially with $\mathrm{CO}_{2} / \mathrm{H}_{2} \mathrm{O}$ bulk composition which might be due to lower $\mathrm{H}_{2} \mathrm{O}$ abundance derived from VIRTIS-H instrument compared to ROSINA near perihelion, while $\mathrm{CO}_{2}$ match fairly. It is to be noted that we have used a thermo-physical model in the attempt to directly reproduce the ROSINA/DFMS volatiles density measurements with the sublimation of the nucleus orbiting around the Sun with a given bulk composition. We acknowledge that our model reproduces only partially the observed production rates (Section 2.d, Fig. 4). Peaks of volatiles production rate in good agreements with observations in the northern hemisphere or overestimated in the southern hemisphere. However, the production rate slopes provided by the thermo-physical model are closer to observations than similar thermo-physical model (model A, Keller et al. 2015b) based on first principles approach.

In addition to chemical composition of the nucleus, this direct approach provides us with some additional insight on the physical parameters that can influence the outgassing pattern and then explain the different trends we observe. For instance, we have highlighted in this study both the compositional dichotomy between the northern and southern hemispheres and the importance of the thermal inertia in the outgassing pattern. This model can be adapted to study other comets outgassing in the future.

6. Conclusion 
We used a thermo-physical model with a spherical cometary nucleus to reproduce the volatiles

964

965

966

967

968

969

970

971

972

973

974

975

976

977

978

979

980

981

982

983

984

985

986

987

988

989

density ratios detected in the coma of 67P/C-G by ROSINA/DFMS. For an EAF of 20\%, the thermophysical model provides a reasonable approximation of the global volatiles production rates observed. The production slopes are close (although mostly lower) than the slope obtained for observations and the volatiles peak production rates are consistent for the southern hemisphere but are underestimated in the northern hemisphere by a factor of about 5. In addition, the time of the total $\mathrm{H}_{2} \mathrm{O}$ peak production is shifted of several days closer to perihelion compared to observations.

With the model, we reproduced the trend and order of magnitude of three density ratios $\mathrm{CO} / \mathrm{CO}_{2}, \mathrm{CO}_{2} / \mathrm{H}_{2} \mathrm{O}$ and $\mathrm{CO} / \mathrm{H}_{2} \mathrm{O}$ for several months of the Rosetta mission. The volatiles bulk composition used to reproduce the measurements at different latitudes for each month of the Rosetta mission present some homogeneity with $\mathrm{H}_{2} \mathrm{O}>82 \%$ and $\mathrm{CO}_{2}$ abundance larger than $\mathrm{CO}$. Nonetheless, this results in a heterogeneous coma, as has been observed for 67P/C-G by the various Rosetta payload instruments. This indicates that the outgassing is mainly insolation-driven. Specifically the strong heterogeneities observed in the 67P/C-G coma most probably result from the tilt of the spin axis and the eccentricity of the comet rather than the complex shape of the nucleus. This study provides an absolute estimation of the global volatiles bulk composition of 67P/C-G's nucleus, namely (91.4 \pm $4.5) \% \mathrm{H}_{2} \mathrm{O},(6.7 \pm 3.5) \% \mathrm{CO}_{2}$, and $(1.9 \pm 1.2) \% \mathrm{CO}$.

Even though the nucleus bulk composition exhibits a global homogeneity, our study reveals a distinct composition before the $1^{\text {st }}$ equinox and the period in between the two equinoxes. Indeed, before the $1^{\text {st }}$ equinox the average bulk composition ratio $\mathrm{CO} / \mathrm{CO}_{2}$ required to reproduce the measurements is larger $(0.6 \pm 0.1)$ than the one used to reproduce measurements in between equinoxes $(0.2 \pm 0.1)$. In addition, before the $1^{\text {st }}$ equinox the addition of a dust mantle $(5 \mathrm{~mm})$, and thus a change in thermal inertia, is required at the nucleus surface to fit the experimental data while it is not the case in-between the equinoxes. These differences are thought to reflect a dichotomy between the northern and southern hemispheres most probably due to difference in the solar input and associated evolutionary processes. 
From month to month, we observe an evolution of the volatiles bulk composition with time.

991

992

993

994

995

996

997

998

999

1000

1001

1002

1003

1004

1005

1006

1007

1008

1009

1010

1011

1012

1013

1014

1015

1016

$\mathrm{H}_{2} \mathrm{O}$ percentage decreases (with a relative increase of $\mathrm{CO}_{2}$ and $\mathrm{CO}$ ) during the period before the $1^{\text {st }}$ equinox and similarly for the period in between equinoxes. This evolution is so far not well understood and might be linked to a $\mathrm{H}_{2} \mathrm{O}$ reservoir not represented in our thermo-physical model. The $\mathrm{CO}_{2} / \mathrm{H}_{2} \mathrm{O}$ and $\mathrm{CO} / \mathrm{H}_{2} \mathrm{O}$ bulk composition ratios can locally shift up to 2 orders of magnitude. However, improvement of the correlation is still possible and might modify the bulk composition ratios.

We observe that the illuminated northern hemisphere dominates the outgassing before the $1^{\text {st }}$ equinox, and the illuminated southern hemisphere dominates the outgassing in between equinoxes. The model reproduces fairly the measurement for those periods. After the $2^{\text {nd }}$ equinox the northern plains are illuminated again and one would have expected to observe volatiles composition similar to the ones before the $1^{\text {st }}$ equinox. Although the presence of the dust mantle at the surface is still necessary, the reproduction of ratios trend is not always satisfying our correlation criteria. In particular we see divergence close to the $2^{\text {nd }}$ equinox period and for $\mathrm{CO} / \mathrm{H}_{2} \mathrm{O}$ density ratios. We suspect that after the $2^{\text {nd }}$ equinox the outgassing pattern is influenced by contributions from both hemispheres and nonradial outgassing. Even if the southern hemisphere is no longer illuminated, the thermal inertia of the nucleus influences the outgassing of the most volatile species such as CO. We assume a similar behaviour around the $1^{\text {st }}$ equinox while the activity of the nucleus move from the North towards the South to explain the discrepancies observed between the numerical results and measurements. This observation in addition to the requirement to add sometimes a desiccated dust mantle at the nucleus surface illustrates the non-negligible role played by thermal inertia on the outgassing pattern. This must be carefully taken into account while interpreting observations.

The internal structure of the nucleus is thought to be differentiated according to the different sublimation fronts of the species. Lateral compositional variation will be caused by variation in surface activity distribution and illumination from one area to another and even be enhanced by the complex shape of the nucleus. 
(due to the global $\mathrm{H}_{2} \mathrm{O}$ overproduction with the thermos-physical model) compared to the observations, especially for the southern hemisphere. Values must be considered as an upper limit. and the creation of a "harder" layer close to the nucleus surface which was observed by the lander Philae.

In order to improve our chemical and physical constraints on 67P/C-G's nucleus, further investigations need to be performed. In particular, additional free parameters can be varied to study their influence on the outgassing pattern. For instance, the investigation of the influence of the dust properties and content, porosity, thermal inertia or the ice phases (clathrate and amorphous). The absolute volatiles production curves might be improved by better take into account the input energy of a given area and the fraction of exposed volatiles at the nucleus surface. This model can also be applied to study the composition of other comets. Hence, we are in effect calibrating the model against 67P/C-G to improve our understanding of what remains a complex tool.

The team from the University of Bern is supported through the Swiss National Science Foundation and through the NCCR PlanetS. The project has also received funding from the European Union's Horizon 2020 research and innovation program under grant agreement No 686709. This work was supported by the Swiss State Secretariat for Education, Research and Innovation (SERI) under contract number 16.0008-2. The opinions expressed and arguments employed herein do not necessarily reflect the official views of the Swiss Government. All ROSINA data are the work of the international ROSINA team (scientists, engineers and technicians from Switzerland, France, Germany, Belgium and the US) over the past 25 years, which we herewith gratefully acknowledge. Rosetta is an 
thanks to the ESA Planetary Science Archive. Raphael Marschall acknowledges the support from the Swiss National Science Foundation grant 184482. Olivier Mousis acknowledges support from CNES.

Accomazzo, A. et al. (2017). The final year of the Rosetta mission. Acta Astronautica, 136, 354-359.

A’Hearn, M. F. et al., (2011). EPOXI at comet Hartley 2. Science, 332, 1396-1400.

Attree, N. et al., (2017). Tensile strength of 67P/Churyumov-Gerasimenko nucleus material from overhangs. A\&A, 611, A33.

Auger, A. T. et al. (2018). Meter-scale thermal contraction crack polygons on the nucleus of comet 67P/Churyumov-Gerasimenko. Icarus, 301, 173-188.

Balsiger, H. et al., (2007). Rosina - Rosetta orbiter spectrometer for ion and neutral analysis. Space Science Reviews, 128(1-4), 745-801.

Bardyn, A. et al., (2017). Carbon-rich dust in comet 67P/Churyumov-Gerasimenko measured by COSIMA/Rosetta. MNRAS, 469, S712-S722.

Biver, N. et al. (2019). Long-term monitoring of the outgassing and composition of comet 67P/Churyumov-Gerasimenko with the Rosetta/MIRO instrument. A\&A, 630, A19.

Bockelée-Morvan, D. et al. (2015). First observations of $\mathrm{H} 2 \mathrm{O}$ and $\mathrm{CO} 2$ vapor in comet 67P/Churyumov-Gerasimenko made by VIRTIS onboard Rosetta, A\&A, 583, A6. 
1071

1072

1073

1074

1075

1076

1077

1078

1079

1080

1081

1082

1083

1084

1085

1086

1087

1088

1089

1090

1091

1092

1093

1094

1095

1096

1097

1098

Bockelée-Morvan, D. et al. (2016). Evolution of CO2, CH4, and OCS abundances relative to $\mathrm{H} 2 \mathrm{O}$ in the coma of comet 67P around perihelion from Rosetta/VIRTIS-H observations. MNRAS, 462, S170S183.

Boehnhardt H. et al. (2017). The Philae lander mission and science overview. Philosophical Transactions of the Royal Society A-Mathematical Physical and Engineering Sciences, 375(2097), 20160248.

Brugger, B. et al., (2016). Subsurface Characterization of 67P/Churyumov-Gerasimenko's Abydos Site. The Astrophysical Journal, 822(2).Capaccionni, F., et al., (2015). The organic-rich surface of comet 67P/Churyumov-Gerasimenko as seen by VIRTIS/Rosetta. Science, 347(6220).

Capria, M. T., et al. (2017). How pristine is the interior of the comet 67P/Churyumov-Gerasimenko.

MNRAS, 469, S685-S694.

Combi, M., et al. (2020). The surface distributions of the production of the major volatile species, $\mathrm{H}_{2} \mathrm{O}, \mathrm{CO}_{2}$, $\mathrm{CO}$ and $\mathrm{O}_{2}$, from the nucleus of comet 67P/Churyumov-Gerasimenko throughout the Rosetta Mission as measured by the ROSINA double focusing mass spectrometer. Icarus, 335, 113421. doi: 10.1016/j.icarus.2019.113421.

Choukroun, M. et al., (2020). Dust-to-gas and refractory-to-ice mass ratios of comet 67P/ChuryumovGerasimenko from Rosetta observations. Space Science Reviews, 216(3), 44.

Ciarniello, M. et al. (2015). Photometric properties of comet 67P/Churyumov-Gerasimenkofrom VIRTIS-M onboard Rosetta. A\&A, 583, A31.

De Sanctis, M. C. et al., (2010). Shape and obliquity effects on the thermal evolution of the Rosetta target 67P/Churyumov-Gerasimenko cometary nucleus. Icarus, 2017, 341-358. 
1100 De Sanctis, M. C. et al., (2015). The diurnal cycle of water ice on comet 67P/Churyumov-

1101 Gerasimenko. Nature, 525(7570), 500-503.

El-Maary, M. R. et al., (2016). Regional surface morphology of comet 67P/Churyumov-Gerasimenko

from Rosetta/OSIRIS images: The southern hemisphere. A\&A, 593, A110.

El-Maary, M. R. et al., (2017). Surface changes on comet 67P/Churyumov-Gerasimenko suggest a more active past. Science, 355(6332), 1392-1395.

Ellsworth, K. and Schubert, G. (1983). Saturn's icy satellites - Thermal and structural models. Icarus, 54(3), 490-510.

Espinasse, S., et al., (1991). Modeling of the thermal behavior and of the chemical differentiation of cometary nuclei. Icarus, 92(2), 350-365.

Feaga, L. M. et al., (2007). Asymmetries in the distribution of $\mathrm{H} 2 \mathrm{O}$ and $\mathrm{CO} 2$ in the inner coma of Comet 9P/Tempel 1 as observed by Deep Impact. Icarus, 190, 345-356.

Faega, L. M. et al., (2015). Far-UV phase dependence and surface characteristics of comet

Filacchione, G. et al., (2016). Seasonal exposure of carbon dioxide ice on the nucleus of comet 67P/Churyumov-Gerasimenko. Science, 354(6319), 1563-1566.

Filacchione, G. et al., (2016). Seasonal exposure of carbon dioxide ice on the nucleus of comet 67P/Churyumov-Gerasimenko. Science, 354(6319), 1563-1566. 
1127 Filacchione, G. et al., (2020). An orbital water-ice cycle on comet 67P from colour changes. Nature, 1128 578(7793), 49-52.

Fink, U. et al., (2016). Investigation into the disparate origin of $\mathrm{CO} 2$ and $\mathrm{H} 2 \mathrm{O}$ outgassing for Comet 67/P. Icarus, 277, 78-97.

Fornasier, S. et al., (2016). Rosetta's comet 67P/Churyumov- Gerasimenko sheds its dusty mantle to reveal its icy nature. Science, 354(6319), 1566-1570.

Fornasier, S. et al., (2019). Surface evolution of the Anhur region on comet 67P/ChuryumovGerasimenko from high-resolution OSIRIS images. A\&A, 630, A13.

Fougere, F. et al., (2016). Direct Simulation Monte Carlo modelling of the major species in the coma of comet 67P/Churyumov-Gerasimenko. Monthly Notices of the Royal Astronomical Society, 462, S156-S169.

Fulle, M. et al. (2017). The dust-to-ices ratio in comets and Kuiper belt objects. MNRAS, 469, S45S49. MNRAS469,S45-S49. doi:10.1093/mnras/stx983.

Fulle, M. et al., (2016a). Evolution of the dust size distribution of comet 67/Churyumov-Gerasimenko from 2.2 au to perihelion. The Astrophysical Journal, 821.

Fulle, M. et al., (2016b). Unexpected and significant findings in comet 67P/Churyumov-Gerasimenko: an interdisciplinary view. Monthly Notices of the Royal Astronomical Society, 462, S2-S8.

Gasc, S. et al., (2017). Change of outgassing pattern of 67P/Churyumov-Gerasimenkoduring the March 2016 equinox as seen by ROSINA. MNRAS, 469, S109-S117. 
Greenberg, J. M., (1998). Making a comet nucleus. A\&A, 330, 375-380.

1157 Groussin, O., et al., (2015). Temporal morphological changes in the Imhotep region of comet 67P/Churyumov-Gerasimenko. A\&A, 583, A36.

Groussin, O. et al., (2019). The thermal, mechanical, structural, and dielectric properties of cometary nuclei after Rosetta. Space Science Reviews, 215(5), 29.

Guilbert-Lepoutre, A. et al. (2016). Modelling the evolution of a comet subsurface: implications for 67P/Churyumov-Gerasimenko. MNRAS, 462, S146-S155.

Gulkis, S. et al., (2015). Subsurface properties and early activity of comet 67P/Churyumov-

Gerasimenko. Science, 347, aaa0709. doi: 10.1126/science.aaa0709.

Hansen, K. et al., (2016). Evolution of water production of 67P/Churyumov-Gerasimenko: anempirical model and a multi-instrument study. MNRAS, 462, S491 - S506. doi:10.1093/mnras/stw2413.

Hässig, M. et al., (2015). Time variability and heterogeneity in the coma of 67P/ChuryumovGerasimenko. Science, 347(6220).

Herique, A., et al. (2016). Cosmochemical implications of CONSERT permittivity characterizationof 67P/CG. MNRAS, 462, 516-532. doi:10.1093/mnras/stx040.

Hoang, M. et al., (2019). Two years with comet 67P/Churyumov-Gerasimenko: $\mathrm{H} 2 \mathrm{O}, \mathrm{CO} 2$, and $\mathrm{CO}$ as seen by the ROSINA/RTOF instrument of Rosetta. A\&A, 630, A33. 
Hoang, M. et al., (2017). The heterogeneous coma of comet 67P/Churyumov-Gerasimenko as seen by ROSINA: H2O, CO2, and CO from September 2014 to February 2016. A\&A, 600, A77.

Hu, X. et al., (2017). Seasonal erosion and restoration of the dust cover on comet 67P/ChuryumovGerasimenko as observed by OSIRIS onboard Rosetta. A\&A, 604, A114.

Huebner, W. F. (2002). Composition of comets: Observations and models. Earth, Moon and Planets, 89, 179-195.

Huebner, W. F. et al., (2006). Heat and Gas Diffusion in Comet Nuclei. ISSI Scientific Report, 258p, ISSN 1608-280X.

Jorda, L. et al., (2016). The global shape, density and rotation of Comet 67P/Churyumov-Gerasimenko from perihelion Rosetta/OSIRIS observations. Icarus, 277, 257-278.

Keller, H. U. et al., (1986). First Halley Multicolour Camera imaging results from Giotto. Nature, 321(6067), 320-326.

Keller, H. U. et al., (2015a). The changing rotation period of comet 67P/Churyumov-Gerasimenko controlled by its activity. Astronomy and Astrophysics, 579, L5.

Keller, H. U. et al., (2015b). Insolation, erosion, and morphology of comet 67P/ChuryumovGerasimenko. Astronomy and Astrophysics, 583, A34.

Keller, H. U. et al., (2017). Seasonal mass transfer on the nucleus of comet 67P/ChuyumovGerasimenko. Monthly Notices of the Royal Astronomical Society, 469, S357-S371.

Kitamura Y. et al., (1985). A model for the hydrogen coma of a comet. Icarus, 61(2), 278-295. 
1211

1212

1213

1214

1215

1216

1217

1218

1219

1220

1221

1222

1223

1224

1225

1226

1227

1228

1229

1230

1231

1232

1233

1234

1235

1236

1237

Klinger, J. et al., (1996). Toward a model of cometary nuclei for engineering studies for future space missions to comets. Planetary and Space Science, 44(7), 637-653.

Klinger, J. (1999). Thermal evolution of comet nuclei. Advances in Space Research, 23(7), 13091318.

Knapmeyer, M. et al., (2018). Structure and elastic parameters of the near surface of Abydos site on comet 67P/Churyumov-Gerasimenko, as obtained by SESAME/CASSE listening to the MUPUS insertion phase. Icarus, 310, 165-193.

Kochan, H. et al., (1989). Crustal strength of different model comet materials. In ESA, Physics and Mechanics of Cometary Materials, 115-119.

Kofman, W. et al., (2015). Properties of the 67P/Churyumov-Gerasimenko interior revealed by CONSERT radar. Science, 349.

Kossacki, K. J. and Czwechowski, L. (2019). Local activities of comets: an indicator of a non-uniform composition. MNRAS, 490, 2050-2055.

Kossacki, K. J. (2015). Comet 67P/Churyumov-Gerasimenko: Hardening of the sub-surface layer. Icarus, $260,464-474$.

Kramer, T. et al., (2017). Seasonal changes in of the volatile density in the coma and on the surface of the comet 67P/Churyumov-Gerasimenko. MNRAS, 469, S20-S28.

Krankowsky, D. et al. (1986). In situ gas and ion measurements at comet Halley. Nature, 321(6067), 326-329. 
1239 Krause, M. et al., (2011). Thermal conductivity measurements of porous dust aggregates: I. 1240 Technique, model and first results. Icarus, 214(1), 286-296.

Langevin, Y. et al., (2016). Typology of dust particles collected by the COSIMA mass spectrometerin the inner coma of 67P/Churyumov Gerasimenko. Icarus, 271, 76-97.

Läuter, M. et al., (2020). The gas production of 14 species from comet 67P/Churyumov-Gerasimenko based on DFMS/COPS data from 2014 to 2016. MNRAS, 498, 3995-4004. doi:10.1093/mnras/staa2643.

Läuter, M. et al., (2019). Surface localization of gas sources on comet67P/Churyumov-Gerasimenko based on DFMS/COPS data. MNRAS, 483, 852-861. Rosetta/ROSINA. Astronomy and Astrophysics, A1, 12.

Maquet, L. (2015). The recent dynamical history of comet 67P/Churyumov-Gerasimenko. Astronomy and Astrophysics, 579, A78.

Marboeuf, U. (2008). Evolution physico-chimique des objets transneptuniens. PhD Thesis, Université de Franche-Comté.

Marboeuf, U. et al., (2008). Composition of Ices in Low-Mass Extrasolar Planets. The Astrophysical Journal, 681(2), 1624-1630. ice: amorphous, crystalline, and clathrate. Astronomy and Astrophysics, 542. 
Marschall, R. et al., (2020a). The Dust-to-Gas ratio, size distribution, and dust fall-back fraction of

Comet 67P/Churyumov-Gerasimenko: Inferences From Linking the Optical and Dynamical Properties

of the Inner Comae. Frontiers in Physics, 8, 227. doi: 10.3389/fphy.2020.00227.

1270

Marschall, R. et al., (2020b). Limitations in the determination of surface emission distributions on

comets through modelling of observational data - A case study based on Rosetta observations. Icarus,

346, 113742. doi: 10.1016/j.icarus.2020.113742.

Marschall, R. et al., (2017). Cliffs versus plains: Can ROSINA/COPS and OSIRIS data of comet

Astrophysics, 605, A112.

Marshall, D. et al., (2017). Spatially resolved evolution of the local $\mathrm{H} 2 \mathrm{O}$ production rates of comet

Massironi, M. et al., (2015). Two independent and primitive envelopes of the bilobate nucleus of comet 67P. Nature, 526, 402-405.

McDonnell, J.A.M. et al., (1986). Dust density and mass distribution near Comet Halley from Giotto observations. Nature, 321, 338-341.

Merouane, S. et al. (2017). Evolution of the physical properties of dust and cometary dust activity from 67P/Churyumov-Gerasimenko measured in situ by Rosetta/COSIMA. MNRAS, 469, 459-474. 
1295 Mousis, O., et al., (2018). Noble Gas Abundance Ratios Indicate the Agglomeration of 1296 67P/Churyumov-Gerasimenko from Warmed-up Ice. The Astrophysical Journal 865. doi:10.3847/2041-8213/aadf89

Mousis, O., et al., (2015). Pits formation from volatile outgassing on 67P/Churyumov-Gerasimenko.

The Astrophysical Journal, 814(1), L5.

Mumma, M. J., et al., (1987). The ortho-para ratio of water vapor in comet P/Halley. A\&A, 187, 419424.

Pätzold, M., et al., (2019). The Nucleus of comet 67P/Churyumov-Gerasimenko - Part I: The global view - nucleus mass, mass-loss, porosity, and implications. MNRAS, 483, 2337-2346. doi: 10.1093/mnras/sty3171.

Pätzold, M., et al., (2016). A homogeneous nucleus for comet 67P/Churyumov-Gerasimenko from its gravity field. Nature, 530, 63-65.

Poch, O. et al., (2016). Sublimation of water ice mixed with silicates and tholins: Evolution of surface texture and reflectance spectra, with implication for comets. Icarus, 267, 154-173.

Pommerol, A. et al., (2015). OSIRIS observation of meter-sized exposures of $\mathrm{H} 2 \mathrm{O}$ ice the surface of 67P/Churyumov-Gerasimenko and interpretation using laboratory experiments. A\&A, 583, A25.

Preusker, F. et al., (2015). Shape model, reference system definition, and cartographic mapping standards for comet 67P/Churyumov-Gerasimenko - Stereo-photogrammetric analysis of 
Prialnik, D. et al., (2004). Modeling the structure and activity of comet nuclei. Comets II, 359-387.

1323

Quirico, E. et al., (2016). Refractory and semi-volatile organics at the surface of comet

67P/Churyumov-Gerasimenko: Insights from the VIRTIS/Rosetta imaging spectrometer. Icarus, 272, $32-47$.

Rickman, H. et al., (1990). Formation of stable dust mantles on short-period comet nuclei. Astronomy and Astrophysics, 237, 524-535.

Rotundi, A. et al., (2015). Dust measurements in the coma of comet 67P/Churyumov-Gerasimenko inbound to the Sun. Science, 347(6220).

Rubin, M. et al., (2019). Elemental and molecular abundances in comet 67P/Churyumov-

Gerasimenko. MNRAS, 489, 594-607.

Schroeder, I. R. H. G. et al., (2019). A comparison between the two lobes of comet 67P/Churyumov-

Gerasimenko based on D/H ratios in $\mathrm{H} 2 \mathrm{O}$ measured with the Rosetta/ROSINA DFMS. MNRAS, 489, $4734-4740$.

Sekanina, Z. (1981). Rotation and precession of cometary nuclei. Annual Review of Earth and

Planetary Sciences, 9, 113-145.

Schoonenberg, D., and Ormel, C. W. (2017). 'Planetesimal Formation near the Snowline: In or Out?' Astronomy \& Astrophysics 602, A21. doi:10.1051/0004-6361/201630013.

Sierks, H. et al., (2015). On the nucleus structure and activity of comet 67P/Churyumov-Gerasimenko. 
1350 Shinnaka, Y. et al., (2017). Imaging observations of the hydrogen coma of comet 67P/Churyumov-

1351 gerasimenko in 2015 September by the Procyon/Laica. Astronomical Journal, 153, 79. doi: $1352 \quad 10.3847 / 1538-3881 / 153 / 2 / 76$

1353

1354 Spohn, T. et al., (2015). Thermal and mechanical properties of the near-surface layers of comet 67P/Churyumov-Gerasimenko. Science, 349(6247), aab0464-1.

Taylor, M. G. G. T. et al., (2017). The Rosetta mission orbiter science overview: the comet phase.

Thomas, N. et al., (2015a). The morphological diversity of comet 67P/Churyumov-Gerasimenko. Science, 347(6220).

Thomas, N. et al., (2015b). Redistribution of particles across the nucleus of comet 67P/ChuryumovGerasimenko. Astronomy \& Astrophysics, 583, A17.

Vincent, J. B. (2015). Large heterogeneities in comet $67 \mathrm{P}$ as revealed by active pits from sinkhole collapse. Nature, 523(7558), 63-66.

1369 Yamamoto, T. (1985). Formation environment of cometary nuclei in the primordial solar nebula. 1370 Astronomy \& Astrophysics, 142, 31-36. 
- ROSINA/DFMS measurements are mostly reproduced with a 1D thermo-physical comet model

- Link between ices bulk composition in the nucleus and volatiles abundance in the coma

- Volatiles outgassing of comet 67P are mainly insolation-driven due to the obliquity

- Results highlight a dichotomy in composition between the North and South hemispheres

- We provide bulk volatiles (H2O, $\mathrm{CO} 2$ and $\mathrm{CO}$ ) composition of the comet 67P

- Dust mantle at the surface of cometary nucleus influence the volatiles outgassing 


\section{Declaration of interests}

$\bigotimes$ The authors declare that they have no known competing financial interests or personal relationships that could have appeared to influence the work reported in this paper.

$\square$ The authors declare the following financial interests/personal relationships which may be considered as potential competing interests: 